\title{
Supporting information: Permanent dipole moments enhance electronic coupling and singlet fission in pentacene
}

Clemens Zeiser ${ }^{1}$, Luca Moretti ${ }^{2}$, Thomas Geiger ${ }^{3}$, Lukas Kalix ${ }^{3}$, Ana M. Valencia ${ }^{4,5}$, Margherita Maiuri ${ }^{2}$, Caterina Cocchi ${ }^{4,5, *}$, Holger F. Bettinger ${ }^{3}$, Giulio Cerullo ${ }^{2, *}$ and Katharina Broch ${ }^{1, *}$

${ }^{1}$ Institute for Applied Physics, University of Tübingen, Auf der Morgenstelle 10, 72076 Tübingen, Germany

${ }^{2}$ IFN-CNR, Dipartimento di Fisica, Politecnico di Milano, Piazza Leonardo da Vinci 32, 20133 Milan, Italy

${ }^{3}$ Institute for Organic Chemistry, University of Tübingen, Auf der Morgenstelle 18, 72076 Tübingen, Germany

${ }^{4}$ Carl von Ossietzky Universität Oldenburg, Institute of Physics, Carl-von-Ossietzky-Straße 9, 26129 Oldenburg, Germany

${ }^{5}$ Humboldt-Universität zu Berlin, Physics Department and IRIS Adlershof, Zum Großen Windkanal 6, 12489 Berlin, Germany

email: caterina.cocchi@uni-oldenburg.de; giulio.cerullo@fisi.polimi.it; katharina-anna.broch@uni-tuebingen.de 


\section{Contents}

1 Materials and Methods $\quad$ S-3

1.1 Synthesis of 2,3-difluoropentacene . . . . . . . . . . . . . . . . S-3

1.2 Experimental methods . . . . . . . . . . . . . . . . . . . S-5

1.3 Theoretical methods and computational details . . . . . . . . . . . S-5

2 Supporting experimental data and fit results $\quad$ S-7

2.1 Results of X-ray reflectivity measurements . . . . . . . . . . . . S-7

2.2 Absorption and fluorescence spectra in solution . . . . . . . . . . . . . S-8

2.3 Fits of the Davydov splittings . . . . . . . . . . . . . . . . S-10

2.4 Photoluminescence spectra . . . . . . . . . . . . . . . . . . . . S-11

2.5 Transient absorption maps at different fluences . . . . . . . . . . . . . . S-12

2.6 Transient absorption maps with $530 \mathrm{~nm}$ excitation wavelength . . . . . . . S-13

2.7 Photodegradation of $1,4,8,11-\mathrm{F} 4 \mathrm{PEN} \ldots \ldots \ldots$. . . . . . . . . . . . . . . . .

2.8 Global analysis results . . . . . . . . . . . . . . . . . . . S-17

2.9 Time traces and global analysis fits . . . . . . . . . . . . . . S-18

2.10 Time trace comparison at different fluences . . . . . . . . . . . . . . . . S-19

3 Calculations $\quad$ S-20

3.1 Models . . . . . . . . . . . . . . . . . . . . . . . . . S-20

3.2 Electronic properties . . . . . . . . . . . . . . . . . S-20

3.3 Excitations . . . . . . . . . . . . . . . . . . . S-24

3.4 Atomic positions . . . . . . . . . . . . . . . . . S-27 


\section{Materials and Methods}

\subsection{Synthesis of 2,3-difluoropentacene}

The bisdiene 1 and dimethyl-1,2,4,5-tetrazine-3,6-dicarboxylate were synthesized as described previously by Vogel et al. and Boger et al., respectively ${ }^{1,2}$. Reagents were used as purchased from Acros Organics, Sigma-Aldrich, TCI Europe or fluorochem. Anhydrous solvents $\mathrm{CH}_{2} \mathrm{Cl}_{2}$, THF, and $n$-hexane were taken from a MBRAUN SPS 800 solvent purification system. Di- $n$-pentylether was dried over $3 \AA$ molecular sieves and degassed prior to use. MPLC chromatography was performed on an Interchim PuriFlash 430 system using pre-packed silica gel columns of appropriate lengths (particle size: $20 \mu \mathrm{m}$ ), solvent mixtures (HPLC grade) are reported in v/v ratios. NMR spectra were recorded on Bruker Avance III HD 400 and Avance III HDX spectrometers at $400 \mathrm{MHz}\left({ }^{1} \mathrm{H}\right), 101 \mathrm{MHz}\left({ }^{13} \mathrm{C}\right)$, and $376 \mathrm{MHz}\left({ }^{19} \mathrm{~F}\right)$ using $\mathrm{CDCl}_{3}$ and $\mathrm{d}_{2}$-TCE as solvents. Residual solvent signals were used for referencing the NMR spectra. High resolution mass spectra were measured on a Finnigan MAT 95 sector field mass spectrometer using electron impact ionization.

\section{6,7-Difluoro-11,12-dimethylene-1,4,9,10-tetrahydro-1,4-etheno-}

anthracene (2). A solution of $1.92 \mathrm{~g}$ (7.05 mmol) 1,2-dibromo-4,5-difluorobenzene and $1.10 \mathrm{~g}$ (7.05 mmol, $1 \mathrm{eq}$ ) 2,3,5,6-tetrakis(methylene)bicyclo[2.2.2] oct-7-ene in toluene (150 $\mathrm{ml}$ ) was cooled to $-55^{\circ} \mathrm{C}$. $6.25 \mathrm{~mL} n$-Butyllithium (1.6 $\mathrm{M}$ in n-hexane, $\left.10 \mathrm{mmol}, 1.4 \mathrm{eq}\right)$ diluted with $n$-hexane $(20 \mathrm{ml})$ were added dropwise over $2 \mathrm{~h}$. After complete addition, the mixture was stirred for $2 \mathrm{~h}$ at this temperature and then allowed to warm to rt overnight. Methanol $(30 \mathrm{ml})$ was added and the solvent was removed under reduced pressure. The residue was purified by flash chromatography (silica gel, $n$-hexane). Light yellow solid; yield $0.780 \mathrm{~g}(2.9 \mathrm{mmol}, 41 \%)$. ${ }^{1} \mathrm{H}-\mathrm{NMR}\left(400 \mathrm{MHz}, \mathrm{CDCl}_{3}\right): \delta=3.48(\mathrm{~m}, \mathrm{~J}=44.5 \mathrm{~Hz}$, $4 \mathrm{H}), 3.95(\mathrm{~m}, \mathrm{~J}=15.7 \mathrm{~Hz}, 2 \mathrm{H}), 4.87$ (s, $2 \mathrm{H}), 5.10(\mathrm{~s}, 2 \mathrm{H}), 6.49$ (m, J = $15.3 \mathrm{~Hz}, 2$ $\mathrm{H}), 6.90(\mathrm{t}, \mathrm{J}=19.0 \mathrm{~Hz}, 2 \mathrm{H}) \cdot{ }^{13} \mathrm{C}\left\{{ }^{1} \mathrm{H}\right\}-\mathrm{NMR}\left(101 \mathrm{MHz}, \mathrm{CDCl}_{3}\right): \delta=31.2(\mathrm{~s}), 52.2(\mathrm{~s})$, $102.1(\mathrm{~s}), 116.8(\mathrm{~m}, \mathrm{~J}=16.9 \mathrm{~Hz}), 130.3(\mathrm{t}, \mathrm{J}=8.8 \mathrm{~Hz}), 133.6(\mathrm{~s}), 133.8(\mathrm{~s}), 143.8(\mathrm{~s})$, $148.6(\mathrm{dd}, \mathrm{J}=14.6,249.9 \mathrm{~Hz}) .{ }^{19} \mathrm{~F}-\mathrm{NMR}\left(376 \mathrm{MHz}, \mathrm{CDCl}_{3}\right): \delta=-141.8$ (t, J = 19.1 $\mathrm{Hz}$ ). HRMS (EI): $\mathrm{m} / \mathrm{z}\left[\mathrm{M}^{+}\right.$.] calcd for $\mathrm{C}_{18} \mathrm{H}_{14} \mathrm{~F}_{2}$ : 268.105808; found: 268.10184

2,3-Difluoro-5,6,7,12,13,14-hexahydro-6,13-ethenopentacene (3). A solution of $0.78 \mathrm{~g}$ (2.93 mmol) 6,7-difluoro-11,12-dimethylene-1,4,9,10-tetrahydro-1,4-ethenoanthracen and $0.35 \mathrm{ml}$ 1,2-dibromobenzene (2.93 mmol, $1 \mathrm{eq})$ in toluene (100) was cooled to $-55{ }^{\circ} \mathrm{C} .2 .75 \mathrm{~mL} n$-Butyllithium (1.6 $\mathrm{M}$ in $n$-hexane, $\left.4.38 \mathrm{mmol}, 1.5 \mathrm{eq}\right)$ diluted with $13 \mathrm{ml} n$-hexane were added dropwise over $2 \mathrm{~h}$. After complete addition, the mixture was 
stirred for $2 \mathrm{~h}$ at this temperature and allowed to warm to rt overnight. Methanol (20 $\mathrm{mL}$ ) was added and the solvent was removed under reduced pressure. The residue was purified by flash chromatography (silica gel, $n$-hexane $/ \mathrm{CH}_{2} \mathrm{Cl}_{2} 4: 1$ ). Yellow solid; yield 0.890 (2.59 mmol, $88 \%$ ). ${ }^{1} \mathrm{H}-\mathrm{NMR}\left(400 \mathrm{MHz}, \mathrm{CDCl}_{3}\right): \delta=3.54(\mathrm{~s}, 4 \mathrm{H}), 3.62(\mathrm{~s}, 4 \mathrm{H})$, $4.31(\mathrm{~m}, \mathrm{~J}=15.7 \mathrm{~Hz}, 2 \mathrm{H}), 6.87(\mathrm{t}, \mathrm{J}=7.0 \mathrm{~Hz}, 2 \mathrm{H}), 6.91(\mathrm{~m}, \mathrm{~J}=10 \mathrm{~Hz}, 2 \mathrm{H}), 7.11$ (t, J $=11.3 \mathrm{~Hz}, 4 \mathrm{H}) \cdot{ }^{13} \mathrm{C}\left\{{ }^{1} \mathrm{H}\right\}-\mathrm{NMR}\left(101 \mathrm{MHz}, \mathrm{CDCl}_{3}\right): \delta=32.7(\mathrm{~s}), 33.3(\mathrm{~s}), 54.1(\mathrm{~s}), 116.7$ $(\mathrm{m}, \mathrm{J}=16.7 \mathrm{~Hz}), 126.1(\mathrm{~s}), 128.9(\mathrm{t}, \mathrm{J}=13.3 \mathrm{~Hz}), 130.7(\mathrm{t}, \mathrm{J}=8.2 \mathrm{~Hz}), 134.2(\mathrm{~s}), 139.4$ (s), $140.0(\mathrm{~s}), 140.4(\mathrm{~s}), 148.4$ (dd, J = 15.4; $248.7 \mathrm{~Hz}) .{ }^{19} \mathrm{~F}-\mathrm{NMR}\left(376 \mathrm{MHz}, \mathrm{CDCl}_{3}\right)$ : $\delta=-141.9(\mathrm{t}, \mathrm{J}=19.2 \mathrm{~Hz})$.

2,3-Difluoro-6,13-dihydro-6,13-ethenopentacene (4). To a solution of $0.2 \mathrm{~g}$ (0.58 mmol) 2,3-difluoro-5,6,7,12,13,14-hexahydro-6,13-ethenopentacene in $\mathrm{CHCl}_{3}(30 \mathrm{~mL})$ $0.26 \mathrm{~g}$ (1.16 mmol, $2 \mathrm{eq})$ DDQ were added in one portion and the resulting mixture was stirred overnight at rt. $\mathrm{CHCl}_{3}(20 \mathrm{~mL})$ and sat. aq. $\mathrm{NaHCO}_{3}$ were added and the organic phase was washed with sat. aq. $\mathrm{NaHCO}_{3}(2 \times 30 \mathrm{~mL})$ and water $(2 \times 20 \mathrm{~mL})$. After drying over $\mathrm{Na}_{2} \mathrm{SO}_{4}$ the solvent was removed under reduced pressure and the residue was purified by flash chromatography (silica gel, $n$-hexane $/ \mathrm{CH}_{2} \mathrm{Cl}_{2} 4: 1$ ). Bright yellow solid; yield $0.150 \mathrm{~g}(0.44 \mathrm{mmol}, 76 \%)$. ${ }^{1} \mathrm{H}-\mathrm{NMR}\left(400 \mathrm{MHz}, \mathrm{CDCl}_{3}\right): \delta=5.30(\mathrm{dt}, \mathrm{J}=0.9 \mathrm{~Hz}$; $2.8 \mathrm{~Hz}, 2 \mathrm{H}), 7.04$ (dd, J = 3.0 Hz, 4.5 Hz, $2 \mathrm{H}$ ), 7.38 (dd, J = 3.1 Hz, $6 \mathrm{~Hz}, 2 \mathrm{H}), 7.43$ $(\mathrm{t}, \mathrm{J}=9.5 \mathrm{~Hz}, 2 \mathrm{H}), 7.63(\mathrm{~s}, 2 \mathrm{H}), 7.71(\mathrm{dd}, \mathrm{J}=3.3 \mathrm{~Hz}, 5.5 \mathrm{~Hz}, 2 \mathrm{H}), 7.72(\mathrm{~s}, 2 \mathrm{H})$. ${ }^{13} \mathrm{C}\left\{{ }^{1} \mathrm{H}\right\}$-NMR $\left(100 \mathrm{MHz}, \mathrm{CDCl}_{3}\right): \delta=32.7(\mathrm{~s}), 33.3(\mathrm{~s}), 54.1(\mathrm{~s}), 116.7(\mathrm{~m}, \mathrm{~J}=16.7$ $\mathrm{Hz}$ ), 126.1 (s), 128.9 (t, J = 13.3 Hz), 130.7 (t, J = 8.2 Hz), 134.2 (s), 139.4 (s), 140.0 (s), $140.4(\mathrm{~s}), 148.4(\mathrm{dd}, \mathrm{J}=15.4,248.7 \mathrm{~Hz}) \cdot{ }^{19} \mathrm{~F}-\mathrm{NMR}\left(376 \mathrm{MHz}, \mathrm{CDCl}_{3}\right): \delta=-141.9(\mathrm{t}, \mathrm{J}$ $=19.2 \mathrm{~Hz})$. HRMS (EI): $\mathrm{m} / \mathrm{z}\left[\mathrm{M}^{+}\right.$.] calcd for $\mathrm{C}_{24} \mathrm{H}_{14} \mathrm{~F}_{2}: 340.105808$; found: 340.10202 .

2,3-Difluoropentacene (2,3-F $\left.{ }_{2} \mathbf{P E N}\right)$. A suspension of $96 \mathrm{mg}(0.28 \mathrm{mmol}) \mathbf{2 , 3 -}$ difluoro-6,13-dihydro-6,13-ethenopentacene in degassed di-n-pentylether was heated to $180{ }^{\circ} \mathrm{C}$ in the dark using an oil bath. To the resulting solution $56 \mathrm{mg}$ (0.28 mmol, $\left.1 \mathrm{eq}\right)$ dimethyl 1,2,4,5-tetrazine-3,6-dicarboxylate were added quickly in one portion. After 90 seconds at $180{ }^{\circ} \mathrm{C}$ the reaction flask was submerged in an ice bath. The precipitate was collected in a PTFE membrane and washed consecutively with $n$-hexane, $\mathrm{CH}_{2} \mathrm{Cl}_{2}$, and ethyl acetate. The product was dried at rt in vacuum for $4 \mathrm{~d}$. Purple solid; yield $23 \mathrm{mg}$ (0.07 mmol, $28 \%$ ). ${ }^{1} \mathrm{H}-\mathrm{NMR}\left(400 \mathrm{MHz}, \mathrm{d}_{2}\right.$-TCE, $\left.120{ }^{\circ} \mathrm{C}\right): \delta=7.34$ (m, $\left.2 \mathrm{H}\right), 7.61$ (t, 2 $\mathrm{H}, \mathrm{J}=9.8 \mathrm{~Hz}), 7.95(\mathrm{~m}, 2 \mathrm{H}), 8.58(\mathrm{~s}, 2 \mathrm{H}), 8.66(\mathrm{~s}, 2 \mathrm{H}), 8.92(\mathrm{~s}, 2 \mathrm{H}) .{ }^{19} \mathrm{~F}$ NMR $(376$ MHz, $\mathrm{d}_{2}$-TCE, $\left.120^{\circ} \mathrm{C}\right): \delta=134.7$ (br, s). HRMS (EI): m/z [M+.] calcd for $\mathrm{C}_{22} \mathrm{H}_{12} \mathrm{~F}_{2}$ : 314.090158; found: 314.08975 . 


\section{$1.2 \quad$ Experimental methods}

Thin films were prepared by organic molecular beam deposition in ultra-high vacuum (base pressure $\mathrm{p}=10^{-8} \mathrm{mbar}$ ), with a final film thickness of $80 \mathrm{~nm}$ determined by $\mathrm{X}$ ray reflectivity (XRR) measurements. Structural characterization was performed on a 3303TT diffractometer (GE) with 1D detector (Meteor 1D, XRD Eigenmann) for XRR and on a Xeuss 2.0 SAXS/WAXS system (Xenocs) with a Dectris Pilatus3 R 300K detector for grazing incidence X-ray wide angle scattering (GIWAXS), in both cases using a wavelength of $1.5406 \AA$. Absorption spectra were measured using a Lambda 950 spectrophotometer (Perkin-Elmer) for the thin films and on a PerkinElmer Lambda 1050 for solution spectra. The fluorescence and excitation spectra measured in solution were obtained on an Agilent Cary Eclipse fluorescence spectrometer. Ultrafast transient absorption (TA) experiments were performed using a Ti:Sapphire chirped pulse amplified source (Coherent Libra), with $4 \mathrm{~mJ}$ output energy, $1 \mathrm{kHz}$ repetition rate, $800 \mathrm{~nm}$ central wavelength and 100 fs pulse duration. Visible excitation pulses with 70 fs duration and $620 \mathrm{~nm}$ (and $530 \mathrm{~nm}$ ) wavelength were generated by an optical parametric amplifier (OPA) pumped by the second harmonic of Ti:sapphire. The broadband white-light continuum (WLC) spanning 550 - $980 \mathrm{~nm}$ for the probe pulses was generated by focusing the $1200 \mathrm{~nm}$ output of a second OPA into a $5 \mathrm{~mm}$-thick YAG plate. The pump and probe pulses were focused to a $350 \mu \mathrm{m}$ and a $175 \mu \mathrm{m}$ diameter spot, respectively. TA spectra were collected by using a fast optical multichannel analyzer working at the full $1-\mathrm{kHz}$ laser repetition rate. From the measured differential transmission, $\Delta T / T$, the differential absorbance is calculated as: $\Delta A \approx-\Delta T / T$. Measurements were performed at room temperature and under vacuum to avoid sample degradation and the TA data have been analysed using a global analysis (GA) ${ }^{3,4}$.

\subsection{Theoretical methods and computational details}

The theoretical results presented in this work are obtained using density functional theory $(\mathrm{DFT})^{5,6}$ and many-body perturbation theory $(\mathrm{MBPT})^{7}$, including the perturbative $G_{0} W_{0}$ approximation ${ }^{8}$ and the solution of the Bethe-Salpeter equation (BSE) ${ }^{9}$. Groundstate geometry optimizations of the individual and dimer molecules are computed with the all-electron code FHI-aims ${ }^{10}$, adopting tight integration grids and TIER2 basis sets ${ }^{11}$. The generalized-gradient approximation for the exchange-correlation potential is adopted in the Perdew-Burke-Ernzerhof ${ }^{12}$ parameterization. Van der Waals interactions are included via the pairwise Tkatchenko-Scheffler scheme ${ }^{13}$. Atomic positions are relaxed 
until the Hellmann-Feynman forces are smaller than $10^{-3} \mathrm{eV} / \AA$. In the optimization of the dimers, we clamp the $\mathrm{C}$ atoms to preserve the assigned herringbone angle, while the other species are allowed to relax freely, see Sec. 3.4 for atomic positions. We checked that the choice of these parameters and in particular of the exchange-correlation potential lead to differences of $5 \mathrm{meV}$ on the band gaps, which are the key quantities in our analysis, against higher-level approximations including a fraction of exact exchange. For the analysis of the partial charges, we used the Hirshfeld partitioning scheme ${ }^{14}$ on top of PBE plus a 0.70 fraction of Hartree-Fock exact exchange. We checked that with this recipe we obtain for all systems frontier levels in excellent agreement with those calculated with $\mathrm{G}_{0} \mathrm{~W}_{0} @$ CAM-B3LYP (see below) ${ }^{15-18}$.

The MOLGW code ${ }^{19}$ is used to compute electronic and optical properties of the optimized geometries. Gaussian-type cc-pVTZ basis sets ${ }^{20}$ are adopted in this step, including the frozen-core approximation and the resolution-of-identity approximation ${ }^{21}$. The hybrid functional CAM-B3LYP ${ }^{22}$ is used in the underlying DFT calculations as a reliable starting point for the $G_{0} W_{0}$ calculations in the considered $\pi$-conjugated molecules ${ }^{23}$. Excitation energies of singlet and triplet states are computed from the BSE. The full problem ${ }^{24}$ is solved in the calculation of singlet excitation energies while the Tamm-Dancoff approximation ${ }^{25}$ is applied to access triplet energies. The latter choice allows alleviating the triplet instability problem for the molecules under study ${ }^{26-28}$. 


\section{Supporting experimental data and fit results}

\subsection{Results of X-ray reflectivity measurements}

X-ray reflectivity (XRR) curves of PEN and the fluorinated compounds are shown in Fig. S1. Thin films of PEN exhibit two second-order Bragg peaks (BPs), which correspond to a thin film and a bulk phase ${ }^{29-31}$.

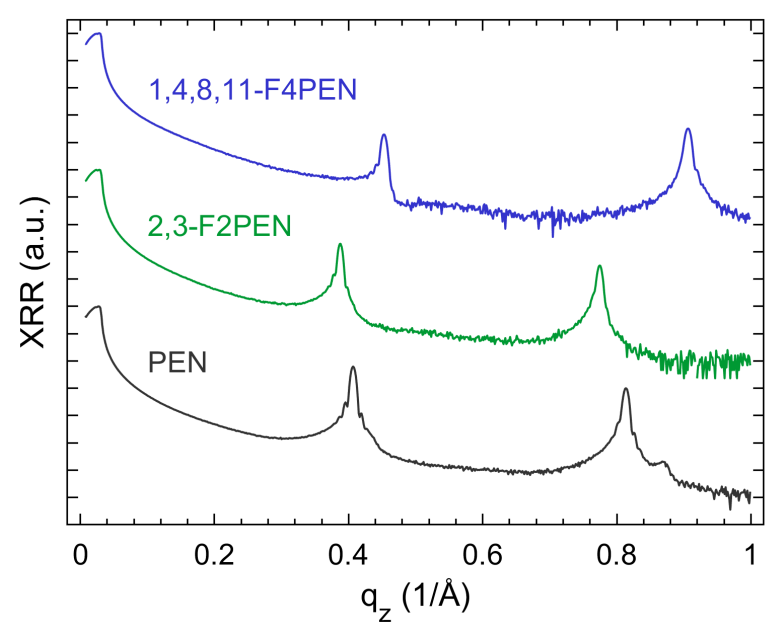

Figure S1: XRR data of pentacene and the fluorinated compounds.

For the lattice spacings and comparison to plane distances of reported unit cells, see Tab. S1. 1,4,8,11- $\mathrm{F}_{4}$ PEN exhibits two BPs that are in agreement with calculated lattice spacings of the reported crystal structure ${ }^{32}$, see Tab. S1. The second-order BP is stronger for $1,4,8,11-\mathrm{F}_{4} \mathrm{PEN}$ than the first-order, which originates from the counteroriented inclination of subsequent, translationally inequivalent molecular planes ${ }^{32}$.

Table S1: Assignment of Bragg-peaks in the XRR data to lattice planes and the corresponding lattice spacing $\left(d_{z}\right)$ of reported structures.

\begin{tabular}{cccccc}
\hline & $q_{z}(1 / \AA)$ & assignment & exp. $d_{z}(\AA)$ & calc. $d_{z}(\AA)$ & Ref. \\
\hline $\mathrm{PEN}$ & 0.8137 & $(002)($ thin film $)$ & 15.44 & 15.40 & 30 \\
$\mathrm{PEN}$ & 0.8703 & $(002)($ bulk $)$ & 14.44 & 14.50 & 31 \\
$2,3-\mathrm{F}_{2} \mathrm{PEN}$ & 0.7740 & - & 16.24 & - & - \\
$1,4,8,11-\mathrm{F}_{4} \mathrm{PEN}$ & 0.9056 & $(040)$ & 27.76 & 27.64 & 32 \\
\hline
\end{tabular}




\subsection{Absorption and fluorescence spectra in solution}

Absorption spectra of PEN, 2,3- $\mathrm{F}_{2} \mathrm{PEN}$ and 1,4,8,11- $\mathrm{F}_{4} \mathrm{PEN}$ in chloroform are shown in Fig. S2a in comparison to the thin film absorption spectra. Absorption, fluorescence and excitation spectra of the newly synthesized $2,3-\mathrm{F}_{2} \mathrm{PEN}$ in dichloromethane are shown in Fig. S2b.

a)

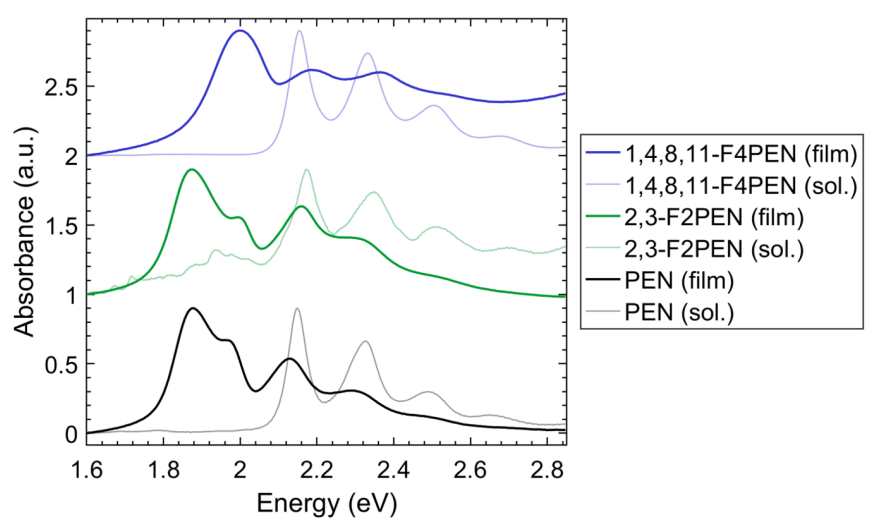

b)

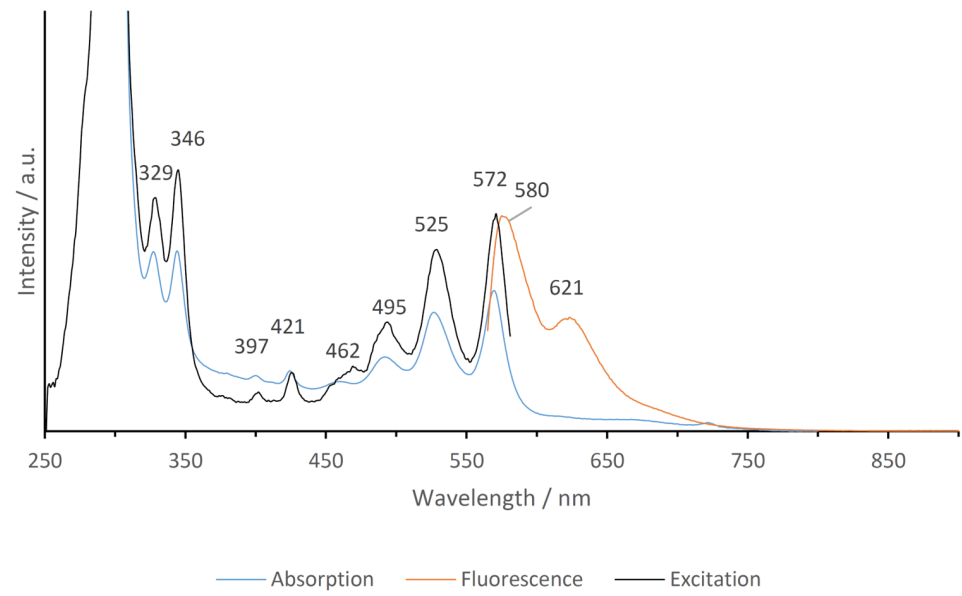

Figure S2: a) Absorption spectra of PEN, 2,3- $\mathrm{F}_{2} \mathrm{PEN}$ and 1,4,8,11- $\mathrm{F}_{4} \mathrm{PEN}$ in chloroform, in comparison to thin film absorption spectra. The weak sub-bandgap absorption for $2,3-\mathrm{F}_{2} \mathrm{PEN}$ results from small aggregates due to the low solubility of the compound. b) Absorption, fluorescence $\left(\lambda_{e x}=296 \mathrm{~nm}\right)$, and excitation spectra $\left(\lambda_{e m}=625 \mathrm{~nm}\right)$ of $2,3-\mathrm{F}_{2} \mathrm{PEN}$ measured in dichloromethane at room temperature.

We have attempted to measure the triplet energy of $2,3-\mathrm{F}_{2} \mathrm{PEN}$ in tetrachloroethane and methyl-THF at $77 \mathrm{~K}$. The solutions were prepared in degassed (5x freeze-pump-thaw) solvents and were transferred to EPR tubes through syringe filters. The concentrations of the solutions were around $10^{-6} \mathrm{M}$ to $10^{-8} \mathrm{M}$. While we could measure fluorescence 
Table S2: Energy of lowest excitation in solution $\left(\mathrm{E}_{\text {sol }}\right)$ and energetic positions of the lower $\left(\mathrm{E}_{D S 1}\right)$ and upper $\left(\mathrm{E}_{D S 2}\right)$ Davydov components. For 1,4,8,11- ${ }_{4} \mathrm{PEN}$, which does not show a Davydov splitting, the given value corresponds to the energy of the lowest excitation in the thin film.

\begin{tabular}{cccc}
\hline & $\mathrm{E}_{\text {sol }}(\mathrm{eV})$ & $\mathrm{E}_{D S 1}(\mathrm{eV})$ & $\mathrm{E}_{D S 2}(\mathrm{eV})$ \\
\hline $\mathrm{PEN}$ & 2.1493 & 1.8776 & 1.9778 \\
$2,3-\mathrm{F}_{2} \mathrm{PEN}$ & 2.1734 & 1.8766 & 1.9981 \\
$1,4,8,11-\mathrm{F}_{4} \mathrm{PEN}$ & 2.1549 & - & 1.9943 \\
\hline
\end{tabular}

and fluorescence excitation spectra for these solutions at room temperature and at $77 \mathrm{~K}$, we were not able to detect phosphorescence. The most diluted solutions gave evidence of aggregation of $2,3-\mathrm{F}_{2} \mathrm{PEN}$ molecules due to change of the fluorescence spectra. We assume that these aggregates are responsible for quenching of the triplet emission and a further reduction of the concentration would be required. This, however, was not feasible due to technical limitations with regards to the sensitivity of the NIR detector. 


\subsection{Fits of the Davydov splittings}

The experimental Davydov splittings (DS) of PEN and 2,3- $\mathrm{F}_{2} \mathrm{PEN}$ have been obtained by fitting gaussian functions to the thin film absorption spectra, see Fig. S3. The fits resulted in a DS of $101 \mathrm{meV}$ for PEN and $125 \mathrm{meV}$ for $2,3-\mathrm{F}_{2} \mathrm{PEN}$.
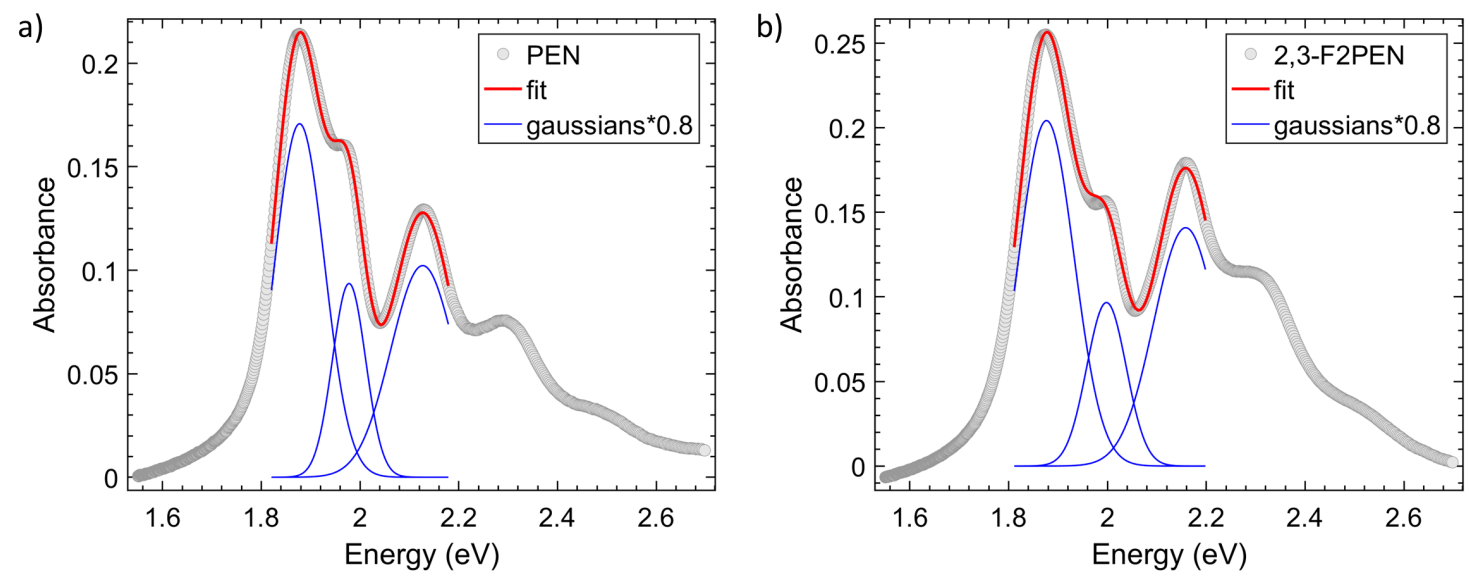

Figure S3: Fits of the DS of PEN and $2,3-\mathrm{F}_{2} \mathrm{PEN}$. The single gaussians are scaled to $80 \%$ of their actual values for better visibility. 


\subsection{Photoluminescence spectra}

Fig. S4 shows PL spectra of PEN and the fluorinated compounds. For 1,4,8,11-F 4 PEN (Fig. S4b) no emission is observed with $633 \mathrm{~nm}$ excitation wavelength. The increase of the PL spectra towards lower energies is a background from the detector. With $532 \mathrm{~nm}$ excitation wavelength a strong PL signal is observed with a maximum above the bandgap of thin films of $1,4,8,11-\mathrm{F}_{4} \mathrm{PEN}$. Upon repeating measurements on the same spot this signal continuously increased in intensity, strongly suggesting it to be connected to the photodegradation of the sample. The maxima at $2.08 \mathrm{eV}$ and $1.92 \mathrm{eV}$ are close to reported maxima of dissolved $1,4,8,11-\mathrm{F}_{4} \mathrm{PEN}\left(2.12 \mathrm{eV}\right.$ and $1.96 \mathrm{eV}$, respectively $\left.{ }^{32}\right)$. Therefore, the PL observed with $532 \mathrm{~nm}$ excitation wavelength likely originates from few molecules which are surrounded by degraded ones and therefore cannot couple resonantly to neighbors anymore.
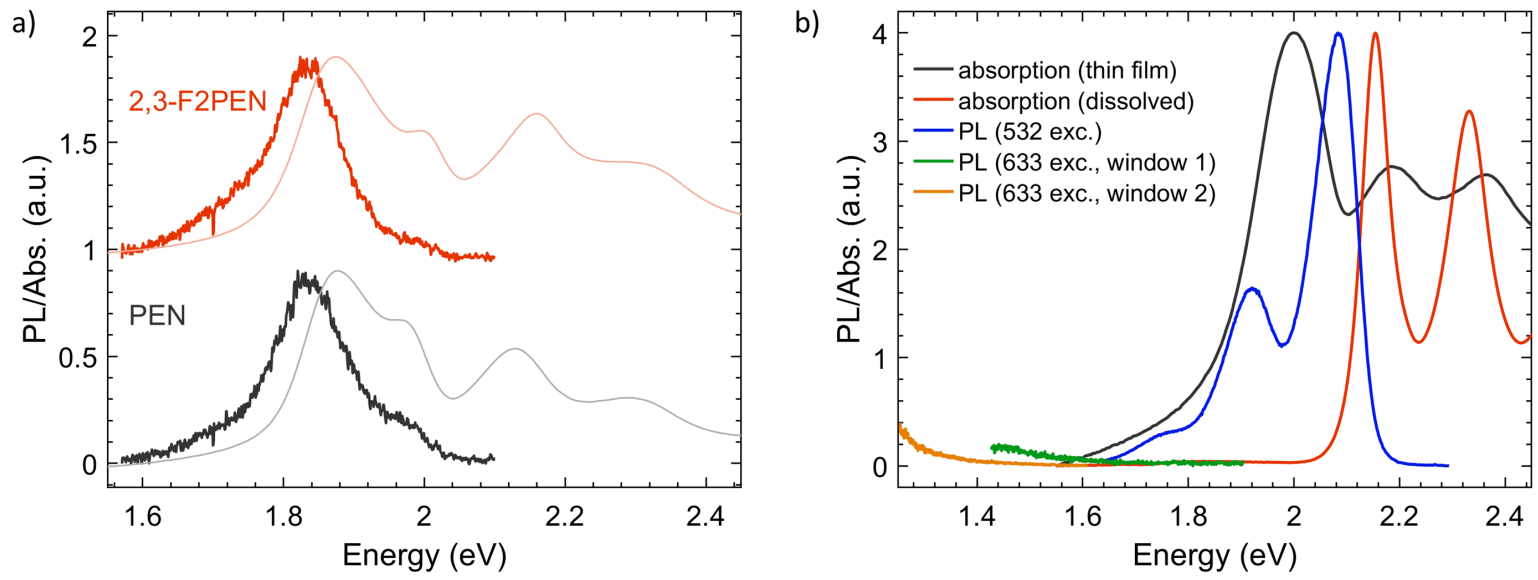

Figure S4: a) Normalized PL spectra (thick lines) of PEN and 2,3- $\mathrm{F}_{2} \mathrm{PEN}$ thin films with $633 \mathrm{~nm}$ excitation wavelength in comparison to the respective absorption spectra (thin lines). b) PL spectra of $1,4,8,11-\mathrm{F}_{4} \mathrm{PEN}$ with two different excitation wavelengths. PL spectroscopy has been performed with a LabRam HR 800 spectrometer (HORIBA Jobin Yvon, France) using a frequency-doubled Nd:YAG laser and a He:Ne laser for $532 \mathrm{~nm}$ and $633 \mathrm{~nm}$ excitation wavelength, respectively. All samples were kept in nitrogen atmosphere during the measurement. 


\subsection{Transient absorption maps at different fluences}

TA maps of thin films of PEN and the fluorinated compounds measured at different fluences are shown in Fig. S5.
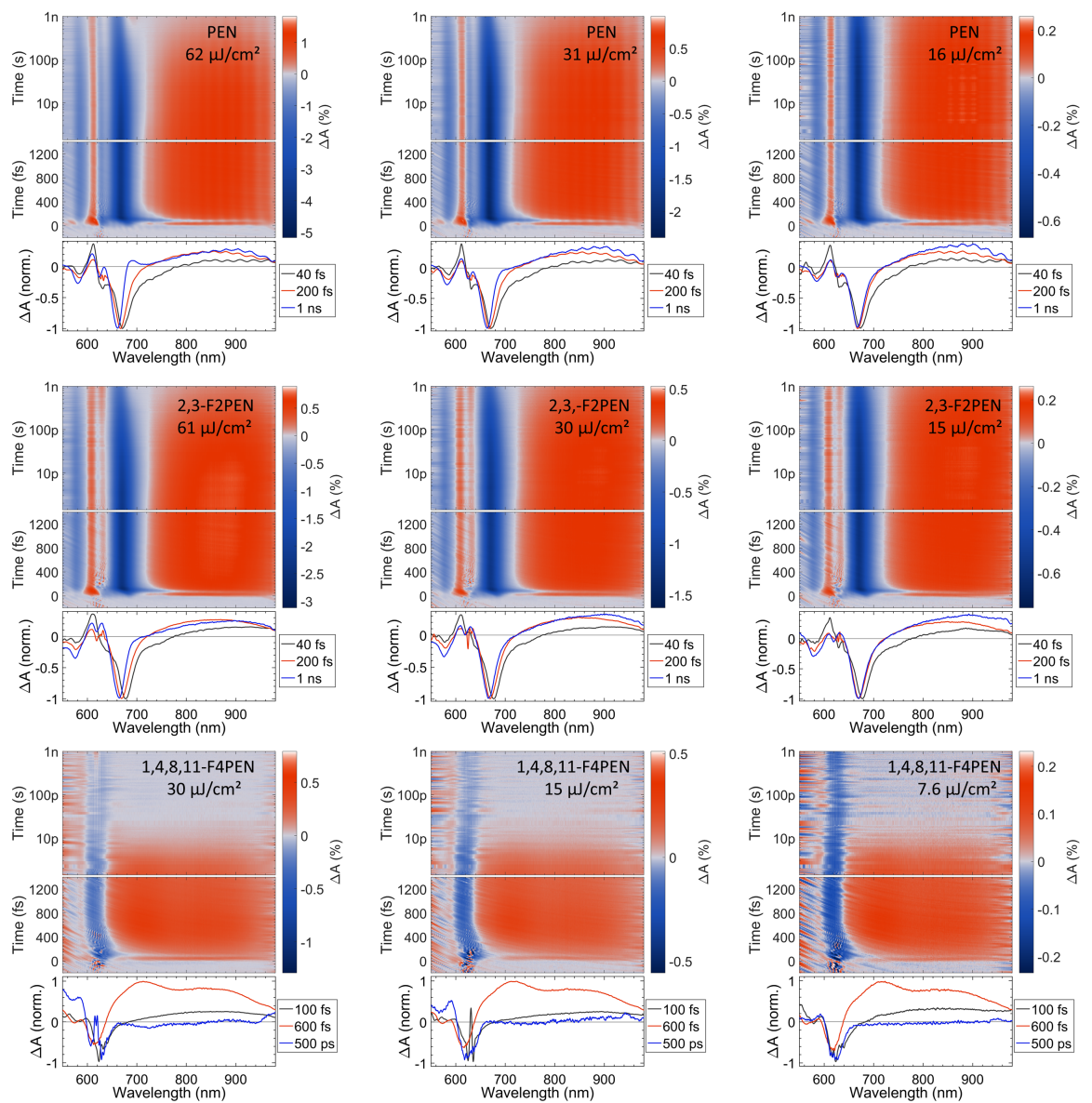

Figure S5: TA maps of PEN and the fluorinated compounds. $\Delta A=-\Delta T / T$ is the change in absorption of the sample upon photoexcitation. For all measurements, an excitation wavelength of $620 \mathrm{~nm}$ has been used. The fluences are shown in the respective panel. Beneath each TA map, TA spectra extracted at different pump-probe delays for the different compounds are shown. 


\subsection{Transient absorption maps with $530 \mathrm{~nm}$ excitation wave- length}

In TA measurements of 1,4,8,11- $\mathrm{F}_{4} \mathrm{PEN}$, the triplet ESA decays with a time constant of approximately $4 \mathrm{ps}$, much faster than for the other compounds. After decay of the triplet ESA, a GSB persists on longer time scales than a nanosecond. Since the GSB is spectrally located exactly at the excitation wavelength, for which a quantitative analysis is more difficult, an additional TA measurement has been performed on 1,4,8,11- $\mathrm{F}_{4} \mathrm{PEN}$ with an excitation wavelength of $530 \mathrm{~nm}$, outside the spectral range of the white light probe. This measurement is shown in Fig. S6 and also exhibits the persistent GSB, proving that it is not an artifact from scattering of the pump pulse.

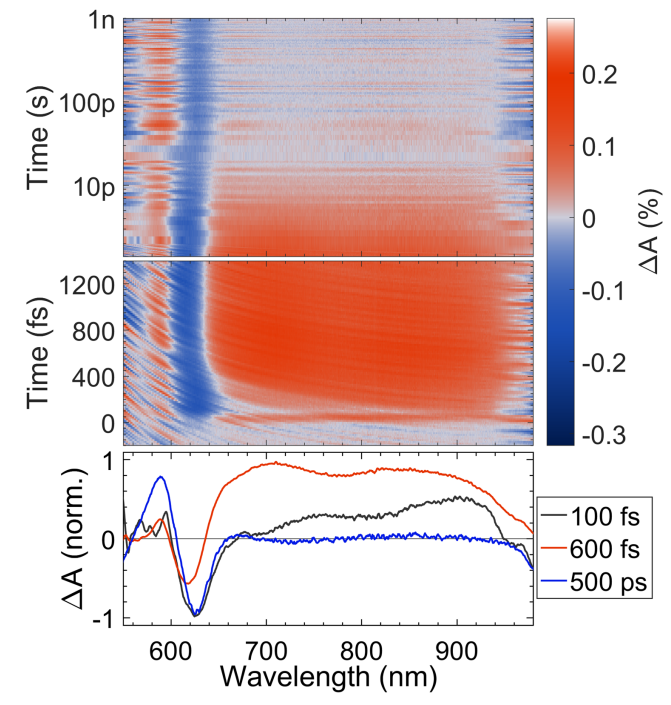

Figure S6: TA measurement on $1,4,8,11-\mathrm{F}_{4} \mathrm{PEN}$ using an excitation wavelength of $530 \mathrm{~nm}$ and a fluence of $15 \mu \mathrm{J} / \mathrm{cm}^{2}$. 


\subsection{Photodegradation of 1,4,8,11-F4PEN}

Thin films of $1,4,8,11-\mathrm{F}_{4} \mathrm{PEN}$ degraded over time in the TA measurements, leading to a continuous decrease of the transmitted probe spectrum (see Fig. S7a) in the region of the $S_{0} \rightarrow S_{1}$ transition of the compound.
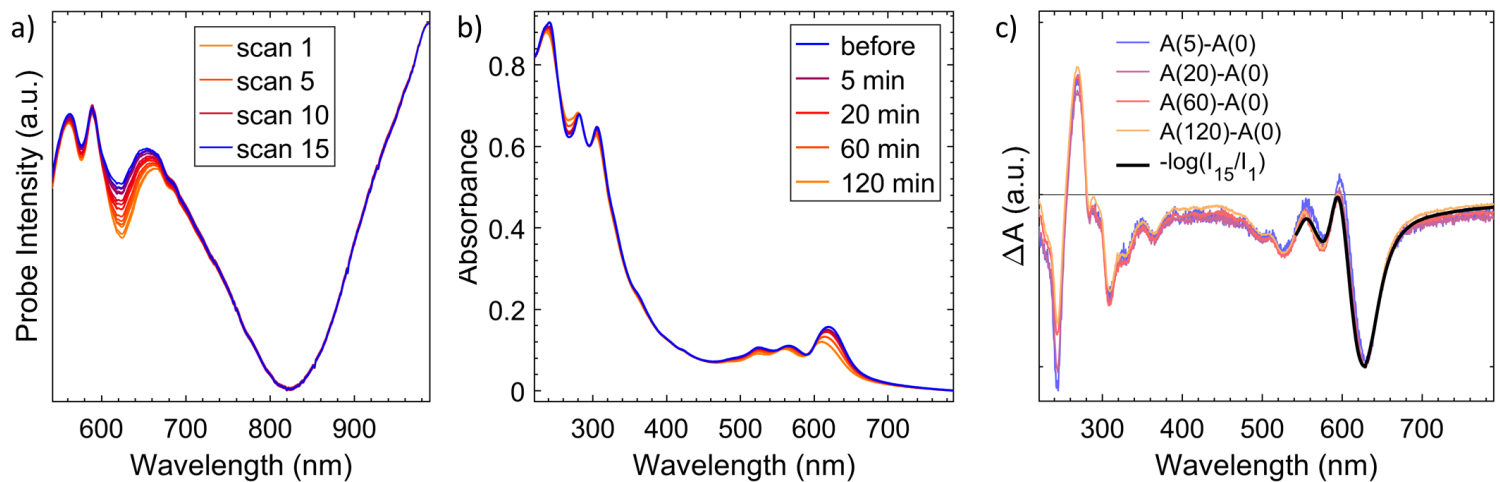

Figure S7: Spectral observation of photodegradation of 1,4,8,11- $\mathrm{F}_{4} \mathrm{PEN}$. a) Transmitted probe spectra for different scans. b) UV-Vis spectra measured after continuous-wave He:Ne laser (633 nm) illumination for different exposure times. c) $\Delta A$ calculated from the absorbance spectra in b) (colored) and from a) (black) as described in the text.

In order to investigate this change in more detail, we performed an illumination experiment with a continuous-wave He:Ne laser $(633 \mathrm{~nm})$ as excitation source, see Fig. S7b, with different exposure times while keeping the sample in protective atmosphere. The degradation can be directly seen with a decrease in absorbance in the region between $500 \mathrm{~nm}$ and $700 \mathrm{~nm}$ and a slight blue-shift. The latter is probably due to a changing polarizability of the molecular environment as molecules degrade. However, only at $270 \mathrm{~nm}$ an increase of the absorbance is observed which could originate from the degradation products. Since this wavelength is much shorter than the excitation wavelength for the TA measurements, we can exclude a direct excitation of degradation products or energy transfer from non-degraded to degraded molecules in these measurements. 
To relate the observed changes in the steady-state absorption spectra with the TA measurements we compare the changes in absorption, see Fig. S7c. The change in sample absorption during the TA measurement $\Delta A(\lambda)$ can be calculated from the transmitted probe spectra $I_{n}(\lambda)$ during scan $n$ (spectra in Fig. S7a), by

$$
\begin{aligned}
\Delta A(\lambda) & =A_{n}(\lambda)-A_{1}(\lambda) \\
& =-\log \left(T_{n}(\lambda)\right)+\log \left(T_{1}(\lambda)\right) \\
& =-\log \left(T_{n}(\lambda) / T_{1}(\lambda)\right) \\
& =-\log \left(I_{n}(\lambda) / I_{1}(\lambda)\right)
\end{aligned}
$$

with the transmittance $T(\lambda)=I(\lambda) / I_{0}(\lambda)$ and the incident probe spectrum $I_{0}(\lambda)$. The resulting $\Delta A(\lambda)$ is shown for the difference between scan 15 and scan 1 in Fig. S7a as black line in Fig. S7c in comparison to the change in absorbance calculated from Fig. S7b (colored lines). The similar shape demonstrates that the observed degradation in Figs. S7a and S7b is of the same origin.

In order to estimate the impact of the observed decrease in the signal on the analysis the single scans were scaled to the same intensity as the first scan before averaging the scans to the final TA map.
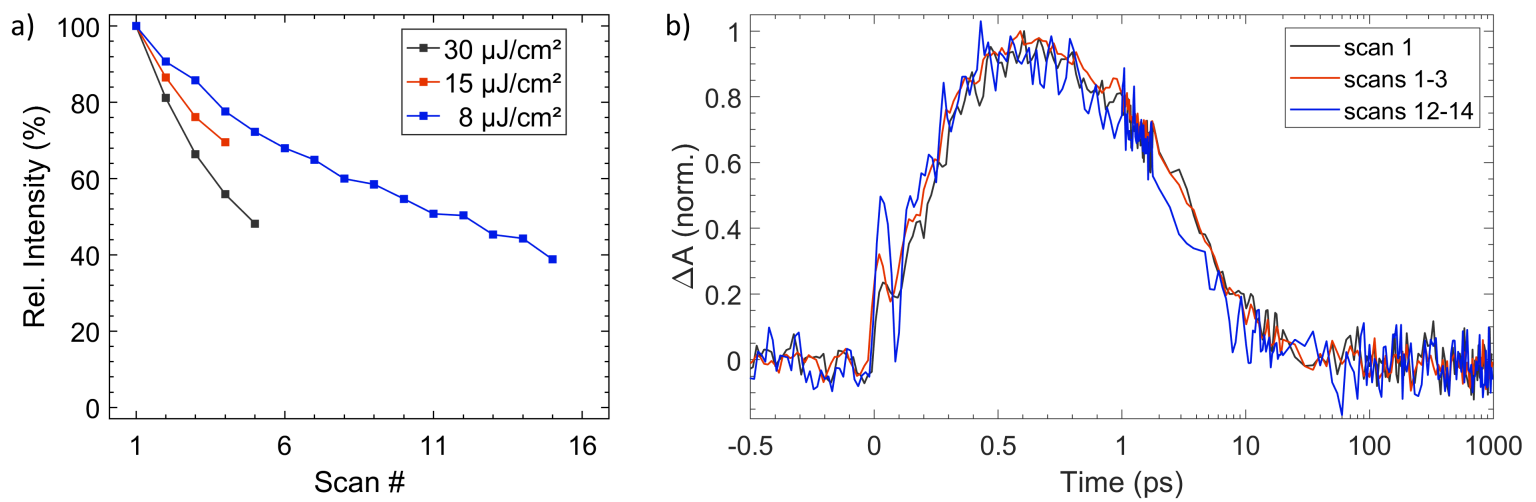

Figure S8: Analysis of the degradation during TA measurements on $1,4,8,11-\mathrm{F}_{4} \mathrm{PEN}$. a) TA signal intensity integrated over the ESA and scaled to the first scan. b) Normalized time traces taken at $750 \mathrm{~nm}$ of TA measurements on $1,4,8,11-\mathrm{F}_{4} \mathrm{PEN}$ with a fluence of $8 \mathrm{\mu J} / \mathrm{cm}^{2}$ and averaged for different numbers of scans (see legend).

Fig. S8b shows traces extracted from TA maps, for which a different number of scans have been averaged. Even though the signal decreased down to $40 \%$ in this measurement, the trace dynamics are not affected. Also note that there is no difference in the traces 
between different fluences (Fig. S11). All analyses were performed on TA maps with three scaled and averaged scans. 


\subsection{Global analysis results}

EAS obtained from GA of TA measurements on thin films of PEN and the fluorinated compounds are shown in Fig. S9. The necessity of more than one triplet species with almost the same TA spectrum for a fit of the TA map corresponds to non-exponential population dynamics of the triplets. These non-exponential population dynamics likely result from triplet-triplet-annihilation (TTA), which is a process described by secondorder rate equations. Since the decay of triplets is not the scope of this study, spectrally similar EAS are shown in grey in Fig. S9.
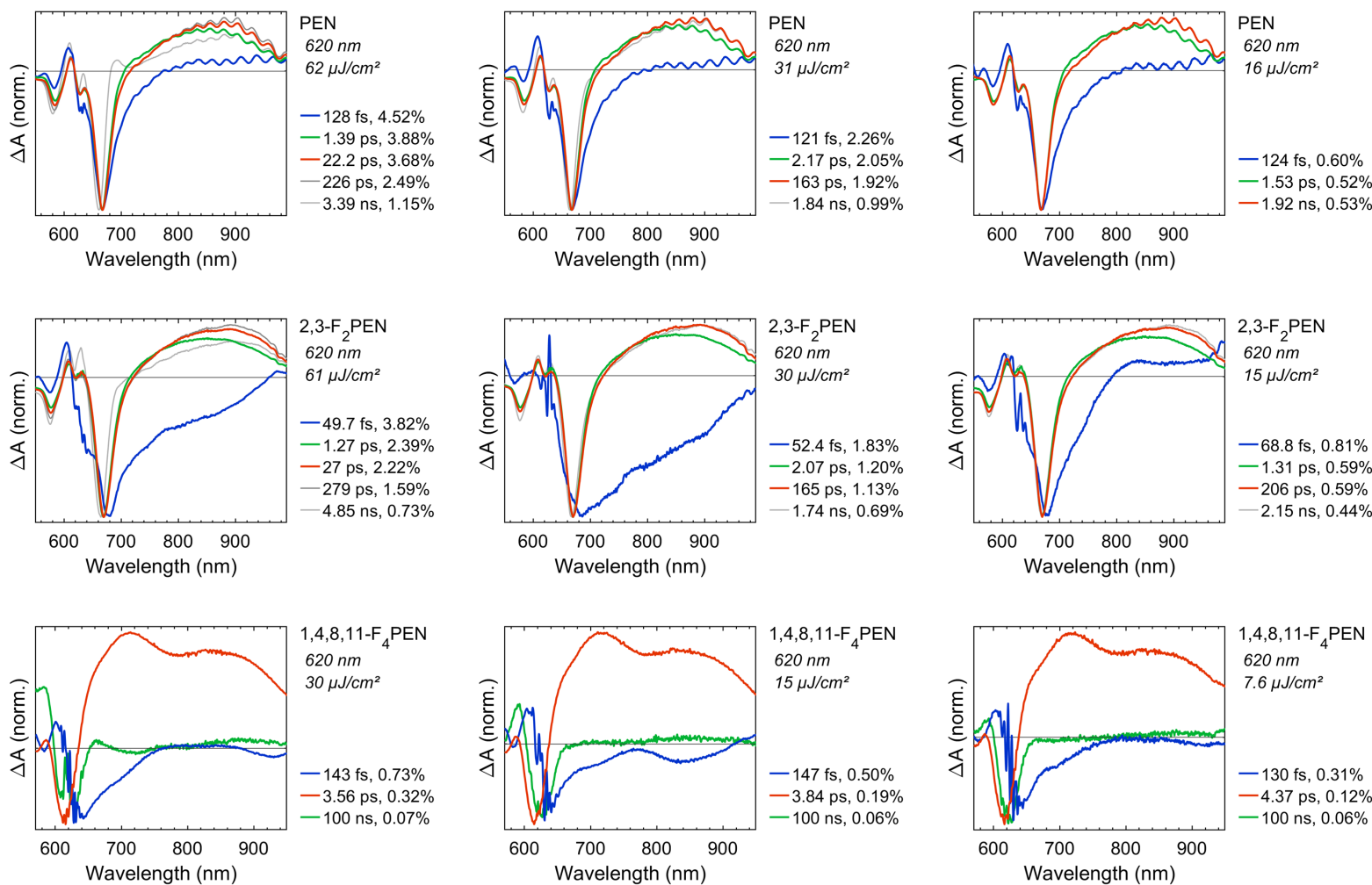

Figure S9: Normalized EAS and time constants of a GA of TA measurements on thin films of PEN and the fluorinated compounds. The legend gives the time constant for the decay into the following species each, as well as the amplitude of the EAS before normalization. 


\subsection{Time traces and global analysis fits}

Time traces and fits extracted from the GAs are shown in Fig. S10.
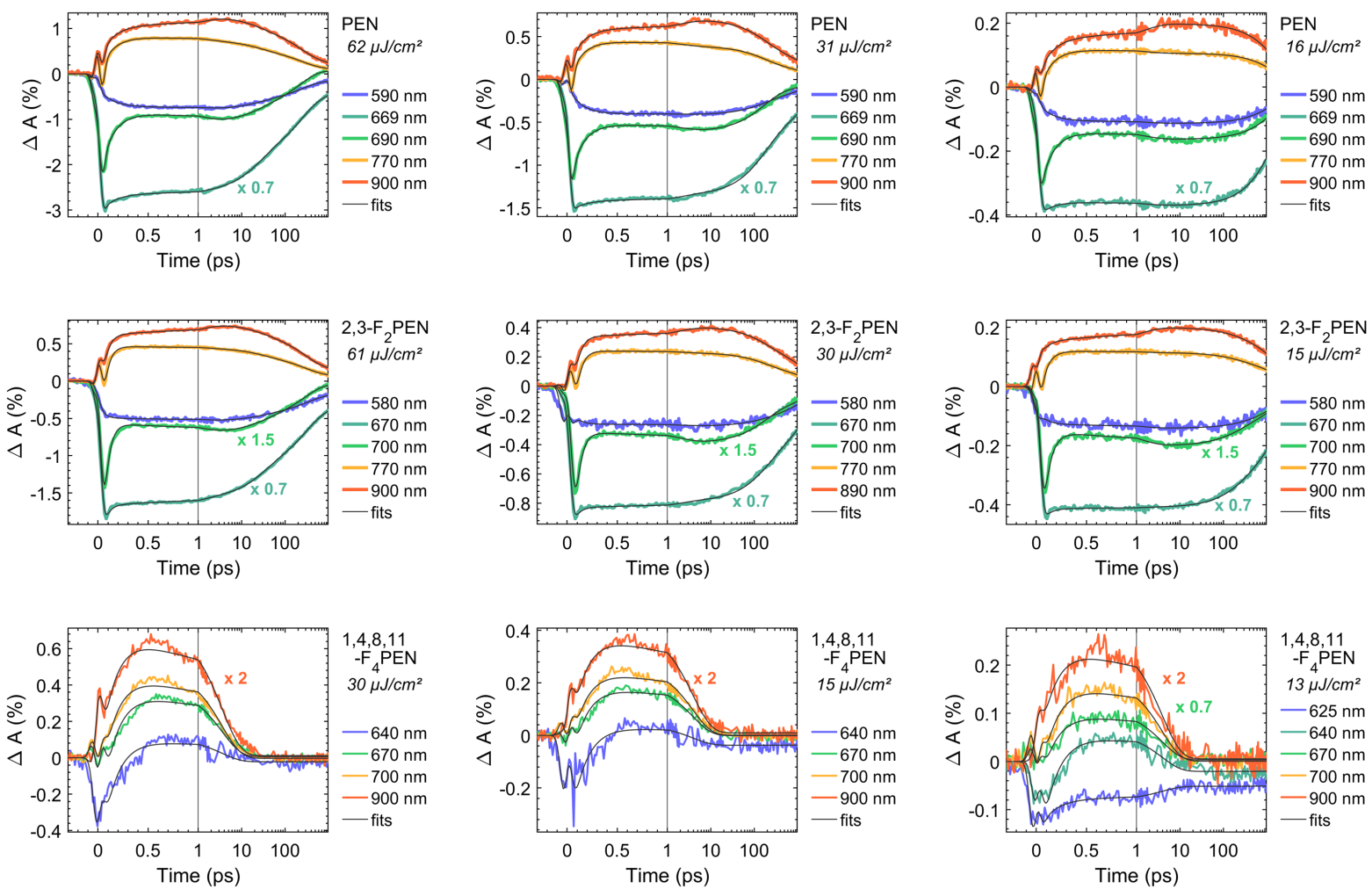

Figure S10: Comparison of selected time traces of TA measurements on thin films of PEN and the fluorinated compounds to the result of the GA. The vertical solid line shows the change from linear to logarithmic scale. 


\subsection{Time trace comparison at different fluences}

Time traces of TA measurements on thin films of PEN and the fluorinated compounds performed with different fluences are shown in Fig. S11.
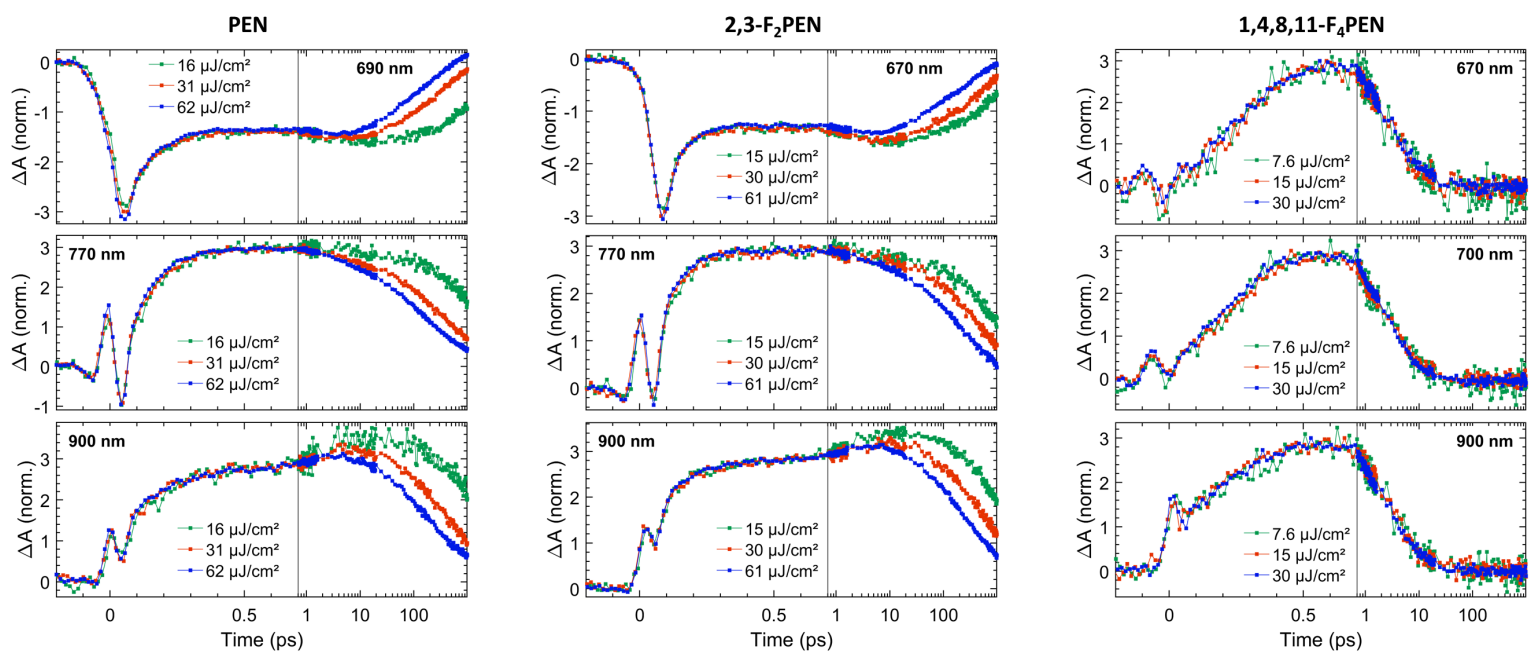

Figure S11: Comparison of different time traces of TA measurements on thin films of PEN and the fluorinated compounds measured with different fluences (see respective legend). 


\section{Calculations}

\subsection{Models}

We model pentacene (PEN), 2,3- $\mathrm{F}_{2} \mathrm{PEN}$, and 1,4,8,11- $\mathrm{F}_{4} \mathrm{PEN}$ as monomers and dimers in vacuo. The geometries of $\mathrm{PEN}$ and $1,4,8,11-\mathrm{F}_{4} \mathrm{PEN}$ are extracted from the corresponding experimental bulk crystal structures ${ }^{32,33}$. The $1,4,8,11-\mathrm{F}_{4} \mathrm{PEN}$ crystal is monoclinic and its unit cell includes two inequivalent molecules arranged in a staircase structure with the molecular planes facing each other at a vertical distance of $3.37 \AA$. In contrast, bulk PEN exhibits a triclinic crystal structure with two inequivalent molecules in the unit cell forming a herringbone pattern.

In the absence of an experimental crystallographic reference for $2,3-\mathrm{F}_{2} \mathrm{PEN}$, we investigate this system in the molecular arrangement of the related 2,3,9,10- $\mathrm{F}_{4} \mathrm{PEN}$ crystal $^{34}$, which also accommodates in the unit cell two inequivalent molecules forming a herringbone angle. For the calculations, the two molecules in the dimer were arranged in the energetically more favourable head-to-tail arrangement of the permanent dipole moments induced by the fluorine atoms at positions 2 and 3 . This assumption about the $2,3-\mathrm{F}_{2} \mathrm{PEN}$ structure is supported by the experimental evidence reported in this article, which indicates that this system crystallizes in an arrangement similar to bulk PEN (and hence to $\left.2,3,9,10-\mathrm{F}_{4} \mathrm{PEN}\right)$ in contrast with the monoclinic lattice of $1,4,8,11-\mathrm{F}_{4} \mathrm{PEN}$.

\subsection{Electronic properties}

Energy levels calculated from $\mathrm{G}_{0} \mathrm{~W}_{0} @ \mathrm{CAM}-\mathrm{B} 3 \mathrm{LYP}$ are plotted in Figure S13 for all considered monomer and dimer structures. In the fluorine-substituted pentacene molecules, the gap region is systematically downshifted compared to PEN: The larger the amount of $\mathrm{F}$ atoms, the lower the energy of the frontier states. This finding is in agreement with the chemical intuition, considering the higher electronegativity of F compared to H. Similar trends were also found in macrocyclic C-conjugated molecules ${ }^{35-38}$. However, this shift is rigid and the size of the gap is essentially unaffected by fluorination being $5.00 \mathrm{eV}$ in the $\mathrm{PEN}$ and 1,4,8,11- $\mathrm{F}_{4} \mathrm{PEN}$ molecules, and $5.03 \mathrm{eV}$ in $2,3-\mathrm{F}_{2} \mathrm{PEN}$.

The frontier orbitals of the dimers emerge from the splitting of the frontier levels of the monomers, such that the resulting band gap is overall reduced compared to the one of the corresponding monomers from the interplay between fluorination and mutual arrangement of the molecules, with the latter effect dominating. This decrease in PEN and in $2,3-\mathrm{F}_{2} \mathrm{PEN}$ is of $0.44 \mathrm{eV}$, while it amounts to only $0.22 \mathrm{eV}$ in $1,4,8,11-\mathrm{F}_{4} \mathrm{PEN}$. In the 
Table S3: Hirshfeld partial charges, expressed as fractions of electrons, on each atoms of PEN, 2,3- $\mathrm{F}_{2} \mathrm{PEN}$, and 1,4,8,11- $\mathrm{F}_{4} \mathrm{PEN}$ molecules. For the labeling of the atoms we refer to Fig. S12.

\begin{tabular}{ll|cc|cc}
\hline PEN & & $2,3-\mathrm{F}_{2} \mathrm{PEN}$ & & $1,4,8,11-\mathrm{F}_{4} \mathrm{PEN}$ & \\
\hline $\mathrm{C} 1$ & -0.005 & $\mathrm{C} 1$ & -0.004 & $\mathrm{C} 1$ & -0.001 \\
$\mathrm{C} 2$ & -0.005 & $\mathrm{C} 2$ & -0.004 & $\mathrm{C} 2$ & -0.001 \\
$\mathrm{C} 3$ & -0.005 & $\mathrm{C} 3$ & -0.005 & $\mathrm{C} 3$ & -0.001 \\
$\mathrm{C} 4$ & -0.005 & $\mathrm{C} 4$ & -0.005 & $\mathrm{C} 4$ & -0.001 \\
$\mathrm{C} 5$ & -0.045 & $\mathrm{C} 5$ & -0.044 & $\mathrm{C} 5$ & -0.037 \\
$\mathrm{C} 6$ & -0.045 & $\mathrm{C} 6$ & -0.044 & $\mathrm{C} 6$ & -0.037 \\
$\mathrm{C} 7$ & -0.004 & $\mathrm{C} 7$ & -0.002 & $\mathrm{C} 7$ & -0.012 \\
$\mathrm{C} 8$ & -0.004 & $\mathrm{C} 8$ & -0.002 & $\mathrm{C} 8$ & -0.012 \\
$\mathrm{C} 9$ & -0.004 & $\mathrm{C} 9$ & -0.004 & $\mathrm{C} 9$ & -0.012 \\
$\mathrm{C} 10$ & -0.004 & $\mathrm{C} 10$ & -0.004 & $\mathrm{C} 10$ & -0.012 \\
$\mathrm{C} 11$ & -0.046 & $\mathrm{C} 11$ & -0.045 & $\mathrm{C} 11$ & -0.037 \\
$\mathrm{C} 12$ & -0.046 & $\mathrm{C} 12$ & -0.045 & $\mathrm{C} 12$ & -0.037 \\
$\mathrm{C} 13$ & -0.046 & $\mathrm{C} 13$ & -0.044 & $\mathrm{C} 13$ & -0.037 \\
$\mathrm{C} 14$ & -0.046 & $\mathrm{C} 14$ & -0.044 & $\mathrm{C} 14$ & -0.037 \\
$\mathrm{C} 15$ & -0.047 & $\mathrm{C} 15$ & -0.046 & $\mathrm{C} 15$ & 0.101 \\
$\mathrm{C} 16$ & -0.0473 & $\mathrm{C} 16$ & -0.046 & $\mathrm{C} 16$ & 0.101 \\
$\mathrm{C} 17$ & -0.0473 & $\mathrm{C} 17$ & -0.057 & $\mathrm{C} 17$ & 0.101 \\
$\mathrm{C} 18$ & -0.0473 & $\mathrm{C} 18$ & -0.057 & $\mathrm{C} 18$ & 0.101 \\
$\mathrm{C} 19$ & -0.0503 & $\mathrm{C} 19$ & -0.048 & $\mathrm{C} 19$ & -0.060 \\
$\mathrm{C} 20$ & -0.0503 & $\mathrm{C} 20$ & -0.048 & $\mathrm{C} 20$ & -0.060 \\
$\mathrm{C} 21$ & -0.0503 & $\mathrm{C} 21$ & 0.097 & $\mathrm{C} 21$ & -0.060 \\
$\mathrm{C} 22$ & -0.0503 & $\mathrm{C} 22$ & 0.097 & $\mathrm{C} 22$ & -0.060 \\
$\mathrm{H} 23$ & 0.0496 & $\mathrm{H} 23$ & 0.050 & $\mathrm{H} 23$ & 0.056 \\
$\mathrm{H} 24$ & 0.0496 & $\mathrm{H} 24$ & 0.050 & $\mathrm{H} 24$ & 0.056 \\
$\mathrm{H} 25$ & 0.0496 & $\mathrm{H} 25$ & 0.050 & $\mathrm{H} 25$ & 0.055 \\
$\mathrm{H} 26$ & 0.0496 & $\mathrm{H} 26$ & 0.050 & $\mathrm{H} 26$ & 0.055 \\
$\mathrm{H} 27$ & 0.0496 & $\mathrm{H} 27$ & 0.052 & $\mathrm{H} 27$ & 0.055 \\
$\mathrm{H} 28$ & 0.0496 & $\mathrm{H} 28$ & 0.052 & $\mathrm{H} 28$ & 0.055 \\
$\mathrm{H} 29$ & 0.0507 & $\mathrm{H} 29$ & 0.051 & $\mathrm{~F} 29$ & -0.120 \\
$\mathrm{H} 30$ & 0.0507 & $\mathrm{H} 30$ & 0.051 & $\mathrm{~F} 30$ & -0.120 \\
$\mathrm{H} 31$ & 0.0507 & $\mathrm{H} 31$ & 0.066 & $\mathrm{~F} 31$ & -0.120 \\
$\mathrm{H} 32$ & 0.0507 & $\mathrm{H} 32$ & 0.066 & $\mathrm{~F} 32$ & -0.120 \\
$\mathrm{H} 33$ & 0.0512 & $\mathrm{H} 33$ & 0.052 & $\mathrm{H} 33$ & 0.066 \\
$\mathrm{H} 34$ & 0.0512 & $\mathrm{H} 34$ & 0.052 & $\mathrm{H} 34$ & 0.066 \\
$\mathrm{H} 35$ & 0.0512 & $\mathrm{~F} 35$ & -0.117 & $\mathrm{H} 35$ & 0.066 \\
\hline & 0.0512 & $\mathrm{~F} 36$ & -0.117 & $\mathrm{H} 36$ & 0.066 \\
\hline
\end{tabular}


a)
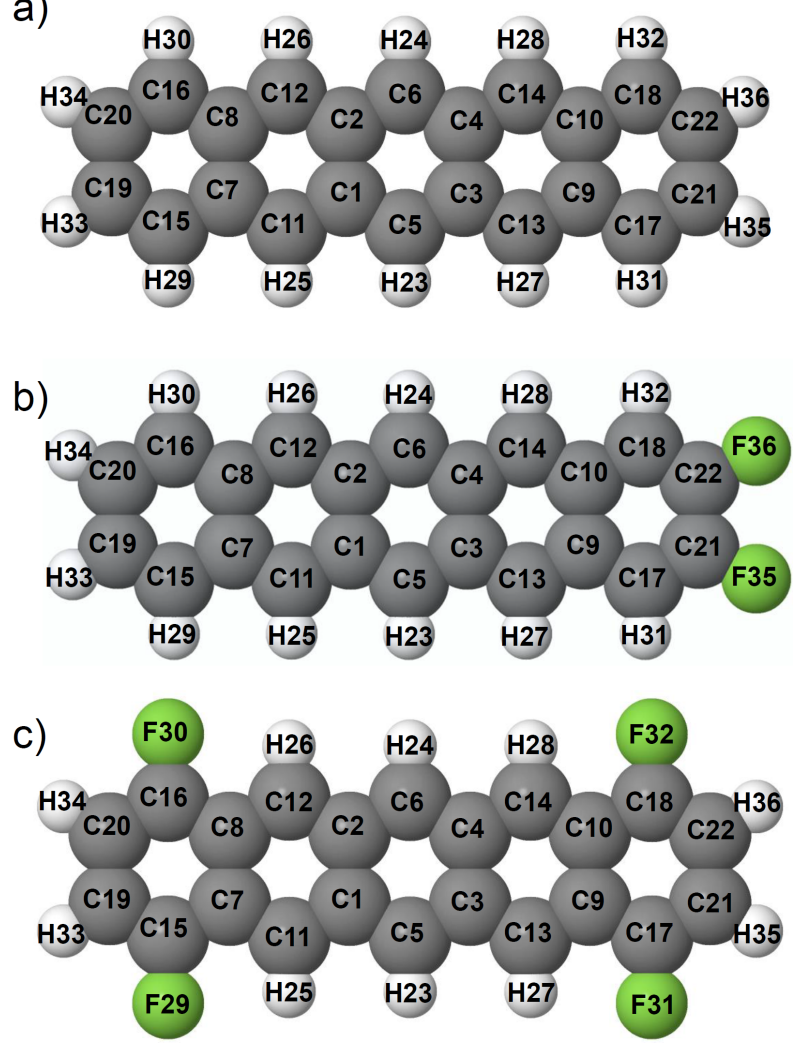

Figure S12: Atom labeling for the Hirshfeld partial charge analysis, see Table S3.

$\mathrm{PEN}$ and $2,3-\mathrm{F}_{2} \mathrm{PEN}$ dimers, where the herringbone angles are $52^{\circ}$ and $48^{\circ}$, respectively, the splitting amounts to a few hundreds of $\mathrm{meV}$ in both the valence and the conduction region, while in 1,4,8,11- $\mathrm{F}_{4} \mathrm{PEN}$ dimer, where the two molecules face each other, it reduces to $100 \mathrm{meV}$ in the occupied region and to $180 \mathrm{meV}$ in the unoccupied states.

The spatial distribution of the molecular orbitals (MOs) is also dependent on the mutual arrangement of the molecules in the dimer. When a herringbone angle is formed between the two molecules, such as in PEN and 2,3- $\mathrm{F}_{2} \mathrm{PEN}$, the highest-occupied $\mathrm{MO}$ (HOMO) and the state directly below it (HOMO-1) are localized on different molecules, and only a residual electronic density is present on the other molecule (see Figure 2, main text). The same holds for the lowest-unoccupied MO (LUMO) and the state directly above it (LUMO+1). Also notice that in PEN and 2,3-F $\mathrm{F}_{2} \mathrm{PEN}$ the HOMO and the LUMO are localized on different molecules. On the other hand, in 1,4,8,11- $\mathrm{F}_{4} \mathrm{PEN}$, where the molecular planes are arranged face-to-face, HOMO and HOMO-1 as well as LUMO and $\mathrm{LUMO}+1$ are equally distributed on both molecules. 


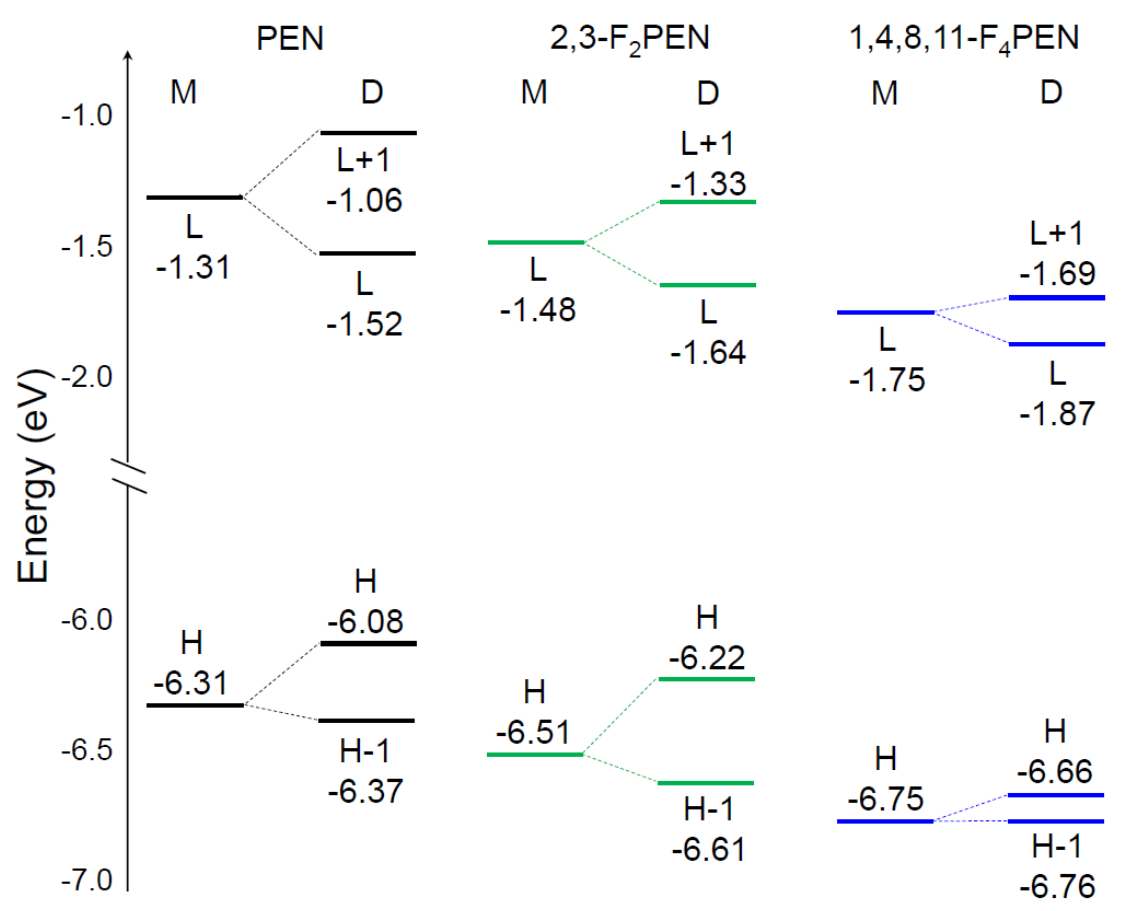

Figure S13: Energy diagram of splitting the frontier energy levels, pentacene (PEN), and the two different fluorinated PEN chromophores, $2,3-\mathrm{F}_{2} \mathrm{PEN}$ and 1,4,8,11- $\mathrm{F}_{4} \mathrm{PEN}, \mathrm{HOMO}(\mathrm{H})$ and LUMO (L), of monomer (M) into dimer (D) molecules. 

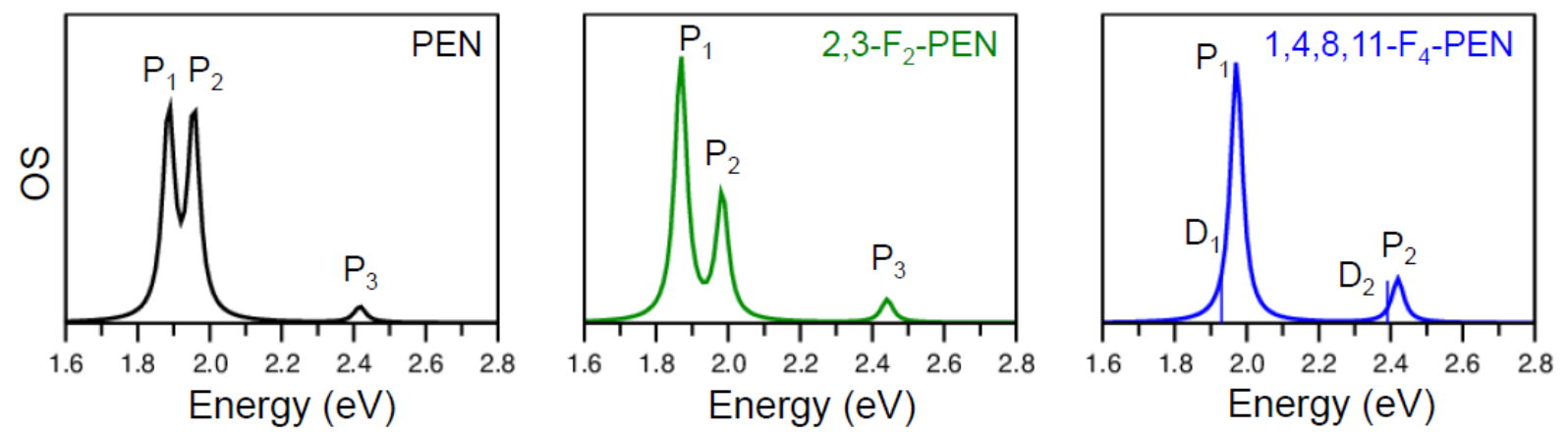

Figure S14: Optical absorption spectra computed for the dimer structures of pentacene (PEN), $2,3-\mathrm{F}_{2} \mathrm{PEN}$, and $1,4,8,11-\mathrm{F}_{4} \mathrm{PEN}$ from left to right panels, respectively. In 1,4,8,11- ${ }_{4} \mathrm{PEN}$ the dark excitations are marked by dashed vertical lines. A Lorentzian broadening of $20 \mathrm{meV}$ is applied to all spectra.

\subsection{Excitations}

The optical spectra of the considered dimers are characterized by a sharp peak at the onset in the visible band (see Figure S14), in agreement with our experimental results. Both PEN and 2,3- $\mathrm{F}_{2} \mathrm{PEN}$ feature a bright excitation at the lowest energy $\left(\mathrm{P}_{1}\right)$, with the one of the former being slightly blue-shifted compared to the latter. In PEN and 2,3$\mathrm{F}_{2} \mathrm{PEN}$, the second excitation, $\mathrm{P}_{2}$, is again optically active, although weaker than $\mathrm{P}_{1}$ in $2,3-\mathrm{F}_{2} \mathrm{PEN}$ dimer. In the considered energy range, a third and much weaker excitation, $\mathrm{P}_{3}$, is found at higher energies. The spectrum of the $1,4,8,11-\mathrm{F}_{4} \mathrm{PEN}$ is qualitatively different from the other two: Only one bright excitation appears at the onset $\left(\mathrm{P}_{1}\right)$ while a dark one appear at lower energy $\left(D_{1}\right)$. At higher energies, in the region where the spectra of $\mathrm{PEN}$ and $2,3-\mathrm{F}_{2} \mathrm{PEN}$ feature $\mathrm{P}_{3}$, we find a weak excitation, labeled $\mathrm{P}_{2}$, again preceded by its dark counterpart, $\mathrm{D}_{2}$. We note that the spectrum of the PEN dimer reproduces qualitatively the features obtained for the bulk, ${ }^{39-43}$ confirming the dominance of local intermolecular interactions ${ }^{44}$.

To gain deeper understanding on the excitations discussed above, we examine their composition in terms of single-particle transitions. As shown in Table S6, in both PEN and 2,3- $\mathrm{F}_{2} \mathrm{PEN}$ dimers, $\mathrm{P}_{1}$ stems mainly from the transition between the HOMO-1 and the LUMO, while $\mathrm{P}_{2}$ from the transition between the $\mathrm{HOMO}$ and the LUMO+1. Notice that both transitions involve occupied and virtual orbitals with maximized overlap, i.e., localized on the same molecule (see Figure 3, main text), which explain the bright character of these excitations. The HOMO $\rightarrow$ LUMO transition, instead, contributes to the largest extent to $\mathrm{P}_{3}$. Due to the localization of the frontier orbitals on different molecules 
Table S4: Quasi particle energy gap $\left(\mathrm{E}_{\text {gap }}\right)$, Singlet bright excitations $\left(\mathrm{P}_{1}\right.$ and $\left.\mathrm{P}_{2}\right)$ in PEN, 2,3$\mathrm{F}_{2} \mathrm{PEN}$, and $1,4,8,11-\mathrm{F}_{4} \mathrm{PEN}$ dimers. The Davydov splitting (DS) computed as the difference between the energy of $\mathrm{P}_{1}$ and $\mathrm{P}_{2}$ in all systems is also reported.

\begin{tabular}{lcccc}
\hline & $\mathrm{E}_{\text {gap }}(\mathrm{eV})$ & $\mathrm{P}_{1}(\mathrm{eV})$ & $\mathrm{P}_{2}(\mathrm{eV})$ & $\mathrm{DS}(\mathrm{meV})$ \\
\hline $\mathrm{PEN}$ & 4.56 & 1.88 & 1.95 & 70 \\
\hline $2,3-\mathrm{F}_{2} \mathrm{PEN}$ & 4.59 & 1.86 & 1.98 & 120 \\
\hline $1,4,8,11-\mathrm{F}_{4} \mathrm{PEN}$ & 4.78 & 1.97 & 2.41 & - \\
\hline
\end{tabular}

Table S5: The lowest-energy excitation obtained from the solution of TDA-BSE. Singlet energy $\mathrm{E}_{\text {singlet }}$, triplet energy $\mathrm{E}_{\text {triplet }}$, and singlet-triplet splitting $\delta(\mathrm{s}-\mathrm{t})$, in $\mathrm{PEN}, 2,3-\mathrm{F}_{2} \mathrm{PEN}$, and $1,4,8,11-\mathrm{F}_{4} \mathrm{PEN}$ dimers.

\begin{tabular}{lccc}
\hline & $\mathrm{E}_{\text {singlet }}(\mathrm{eV})$ & $\mathrm{E}_{\text {triplet }}(\mathrm{eV})$ & $\delta(\mathrm{s}-\mathrm{t})(\mathrm{eV})$ \\
\hline $\mathrm{PEN}$ & 2.20 & 0.88 & 1.32 \\
\hline $2,3-\mathrm{F}_{2} \mathrm{PEN}$ & 2.19 & 0.85 & 1.34 \\
\hline $1,4,8,11-\mathrm{F}_{4} \mathrm{PEN}$ & 2.30 & 0.99 & 1.31 \\
\hline
\end{tabular}

in the dimer (see Figure 2, main text), the oscillator strength of $\mathrm{P}_{3}$ is significantly lower compared to the one of $\mathrm{P}_{1}$ and $\mathrm{P}_{2}$.

In the spectrum of the $1,4,8,11-\mathrm{F}_{4} \mathrm{PEN}$ dimer, the situation is drastically different. At the onset, the spectrum of this system is characterized by only one bright peak $\left(\mathrm{P}_{1}\right)$ at a similar energy as $\mathrm{P}_{2}$ in the other two systems, followed by a weak maximum $\left(\mathrm{P}_{2}\right)$ at higher energies (see Figure S14). Our calculations reveal that both optically active excitations mentioned above are accompanied by a dark excitation at lower energy $\left(D_{1}\right.$ and $\left.D_{2}\right)$. The pairs of bright and dark excitations stem from the same single-particle transitions but in different proportion of the two main contributions. This behavior is in agreement with Kasha's model ${ }^{45}$ and, based on the mutual orientation of the transition-dipole moments in the individual $1,4,8,11-\mathrm{F}_{4} \mathrm{PEN}$ molecules, the dimer acts like a H-aggregate. 
Table S6: Singlet energies, oscillator strength (OS), and composition in terms of single-quasi particle transitions of the first three excitations in PEN, 2,3- $\mathrm{F}_{2} \mathrm{PEN}$, and 1,4,8,11- $\mathrm{F}_{4} \mathrm{PEN}$ dimers. HOMO and LUMO are abbreviated by $\mathrm{H}$ and L, respectively.

\begin{tabular}{|c|c|c|c|c|}
\hline & excitation & Energy (eV) & OS & Composition \\
\hline \multirow[t]{3}{*}{ PEN } & $\mathrm{P}_{1}$ & 1.88 & 0.046 & $\begin{array}{c}\mathrm{H}-1 \rightarrow \mathrm{L}(90 \%) \\
\mathrm{H} \rightarrow \mathrm{L}(10 \%)\end{array}$ \\
\hline & $\mathrm{P}_{2}$ & 1.95 & 0.046 & $\begin{array}{c}\mathrm{H} \rightarrow \mathrm{L}+1(86 \%) \\
\mathrm{H} \rightarrow \mathrm{L}(12 \%)\end{array}$ \\
\hline & $\mathrm{P}_{3}$ & 2.41 & 0.003 & $\begin{array}{c}\mathrm{H} \rightarrow \mathrm{L}(82 \%) \\
\mathrm{H} \rightarrow \mathrm{L}+1(17 \%)\end{array}$ \\
\hline \multirow[t]{3}{*}{$2,3-\mathrm{F}_{2} \mathrm{PEN}$} & $\overline{\mathrm{P}_{1}}$ & 1.86 & 0.059 & $\begin{array}{c}\mathrm{H} \rightarrow \mathrm{L}+1(83 \%) \\
\mathrm{H} \rightarrow \mathrm{L}(16 \%)\end{array}$ \\
\hline & $\mathrm{P}_{2}$ & 1.98 & 0.028 & $\begin{array}{c}\mathrm{H}-1 \rightarrow \mathrm{L}(84 \%) \\
\mathrm{H} \rightarrow \mathrm{L}(11 \%)\end{array}$ \\
\hline & $\mathrm{P}_{3}$ & 2.44 & 0.005 & $\begin{array}{c}\mathrm{H} \rightarrow \mathrm{L}(67 \%) \\
\mathrm{H}-1 \rightarrow \mathrm{L}(17 \%) \\
\mathrm{H}-1 \rightarrow \mathrm{L}+1(10 \%)\end{array}$ \\
\hline \multirow[t]{4}{*}{$1,4,8,11-\mathrm{F}_{4} \mathrm{PEN}$} & $\overline{\mathrm{D}_{1}}$ & 1.93 & 0.000 & $\begin{array}{l}\mathrm{H} \rightarrow \mathrm{L}+1(41 \%) \\
\mathrm{H}-1 \rightarrow \mathrm{L}(58 \%)\end{array}$ \\
\hline & $\mathrm{P}_{1}$ & 1.97 & 0.067 & $\begin{array}{c}\mathrm{H} \rightarrow \mathrm{L}(77 \%) \\
\mathrm{H}-1 \rightarrow \mathrm{L}(23 \%)\end{array}$ \\
\hline & $\mathrm{D}_{2}$ & 2.39 & 0.000 & $\begin{array}{c}\mathrm{H} \rightarrow \mathrm{L}+1(57 \%) \\
\mathrm{H}-1 \rightarrow \mathrm{L}(42 \%)\end{array}$ \\
\hline & $\mathrm{P}_{2}$ & 2.41 & 0.011 & $\begin{array}{c}\mathrm{H}-1 \rightarrow \mathrm{L}+1(74 \%) \\
\mathrm{H} \rightarrow \mathrm{L}(22 \%)\end{array}$ \\
\hline
\end{tabular}


3.4 Atomic positions 
C 2.892160007 .9259300013 .91394000 C 3.865440007 .9304500012 .90405000 C $3.67483000 \quad 8.60455000 \quad 11.67240000$ C 4.639390008 .5668600010 .67380000 C $4.45632000 \quad 9.22453000 \quad 9.42521000$ C $5.41236000 \quad 9.16195000 \quad 8.46192000$ C 6.616370008 .458660008 .68509000 C $6.843330007 .83041000 \quad 9.85883000$ C 5.872280007 .8433400010 .89980000 C 6.070640007 .1846400012 .10178000 C 5.087960007 .2114400013 .12297000 C 6.3815500010 .6204900013 .54812000 H 2.744651569 .1504709111 .50490230 H $3.52816079 \quad 9.772571219 .25623430$ H 7.000472216 .6407700112 .27474000 H $5.4490538510 .25269042 \quad 13.11929003$ C $5.26953000 \quad 6.53187000 \quad 14.33484000$ C $4.29626000 \quad 6.5273500015 .34474000$ C $4.48687000 \quad 5.8532500016 .57638000$ C $3.52231000 \quad 5.8909400017 .57498000$ C $3.70538000 \quad 5.2332700018 .82358000$ C $2.74934000 \quad 5.2958500019 .78686000$ C 1.545330005 .9991400019 .56369000 C 1.318370006 .6273900018 .38996000 C $2.28942000 \quad 6.61446000 \quad 17.34899000$ c 2.091060007 .2731600016 .14700000 C 3.073740007 .2463600015 .12581000 C 6.5668600010 .5279300014 .94643000 C $5.58620000 \quad 9.9557800015 .77977000$ C $5.76429000 \quad 9.85601000 \quad 17.13147000$ C 4.780080009 .2824500018 .01425000 C 4.985200009 .1857500019 .35607000 C 6.218590009 .6663800019 .93517000 C 7.1636300010 .2210000019 .15832000 C $6.97441000 \quad 10.34478000 \quad 17.73176000$ H $6.20326783 \quad 5.9914651014 .50043762$ H 5.420100815 .3141408916 .74676465 H 4.635085224 .6886275618 .99363344 H 1.164270827 .8238287615 .97692194 H 4.662068239 .5940411415 .32755176 H 3.850076528 .9218371217 .57458584 H 4.226878918 .7360243119 .99657582 H $6.36692613 \quad 9.5736930921 .01161366$ C 7.1892700011 .2893100011 .32070000 C 7.3456600011 .1782500012 .70631000 H 5.255797159 .662725307 .58577971 H 7.04907000 11.607095868 .67070833 H 6.2689789810 .9293827910 .85936799 H 7.373672328 .439918297 .90105320 H 7.779513867 .2977295410 .03244750 C 7.9587700010 .9100500016 .92808000 C 7.8023700011 .0211100015 .54248000 H 8.0978612410 .5926496519 .58236462 H $8.8789798011 .27541874 \quad 17.38959084$ C 8.5811800011 .6714300013 .30235000 C 9.5618400012 .2435800012 .46902000 C 9.3837500012 .3433500011 .11731000 C 10.3679600012 .9169100010 .2345400 C 10.1628300013 .013620008 .89272000 C $8.9294500012 .53298000 \quad 8.31362000$ C 7.9844100011 .978360009 .09046000 C 8.1736300011 .8545800010 .51702000 H 10.4835195512 .6152480912 .9224407 H 11.2973836913 .2832086310 .6755225 H 10.9218957513 .454463918 .24724120 H 8.7814516912 .627218307 .23726191

C 8.7664900011 .5788700014 .70067000 H $9.6966038611 .95698728 \quad 15.13041065$ H 1.961537188 .4733069913 .75147823 H $0.38582202 \quad 7.16821638 \quad 18.2194734$

H $0.79179696 \quad 6.02634143 \quad 20.35160899$

H $2.905215314 .79434522 \quad 28.74248366$

Figure S15: Atomic positions used for the PEN dimers. Coordinates given in $\AA$. 
H 1.769376487 .8416300933 .16942318 H $1.75799948 \quad 7.6048367930 .72046705$ C $10.11583000 \quad 0.59684000 \quad 25.43557000$ C 10.053950001 .2383100026 .69034000 C $8.922140001 .16215000 \quad 27.50730000$ H $10.44421297 \quad-0.52946547 \quad 23.00149463$ H $9.24930423 \quad 0.03051766 \quad 25.08955030$ H $8.05450524 \quad 0.59577651 \quad 27.16480802$ H $6.855416291 .17834968 \quad 29.22390831$ F 8.528950294 .1069407821 .13943948 C $9.59480000 \quad 3.92265000 \quad 23.24952000$ C 9.608160004 .0494900024 .58801000 C $8.45378000 \quad 4.56311000 \quad 25.26759000$ C $8.42036000 \quad 4.68837000 \quad 26.66617000$ C $7.28465000 \quad 5.1821200027 .31319000$ $\begin{array}{llll}\text { C } 7.28465000 & 5.18212000 & 27.31319000 \\ \text { C } 5.00189000 & 6.08004000 & 27.18924000\end{array}$ C 6.130650005 .5830900026 .52447000 C 6.179260005 .4526400025 .12910000 C $7.30176000 \quad 4.94480000 \quad 24.48068000$ C $7.34597000 \quad 4.7803800023 .05513000$ C $8.45319000 \quad 4.2816500022 .47757000$ $\begin{array}{llll}\text { C } 8.45319000 & 4.28165000 & 22.47757000 \\ \text { H } 9.29387961 & 4.40073327 & 27.24949039\end{array}$ $\begin{array}{lllll}\text { H } & 9.29387961 & 4.40073327 & 27.24949039 \\ \text { H } & 4.13162015 & 6.38449297 & 26.60464047\end{array}$ H $5.309003145 .74842540 \quad 24.54007980$ H $6.487756605 .05497851 \quad 22.44299613$ H 3.743968227 .2196879134 .50310878 F 7.52538214 4.31212034 34.46723249 F $5.40942422 \quad 2.96034016 \quad 33.60622012$ C 2.644630007 .4501800032 .64883000 C 2.631280007 .3233400031 .31034000 C 3.785650006 .8097200030 .63076000 C $3.81907000 \quad 6.68446000 \quad 29.23218000$ C 4.95479000 6.19071000 28.58516000 C 7.237550005 .292790 11000 C $6.10878000 \quad 5.7897500029 .37388000$ C $6.06018000 \quad 5.9202000030 .76924000$ C $4.93768000 \quad 6.42803000 \quad 31.41766000$ C $4.89346000 \quad 6.59245000 \quad 32.84321000$ C 3.786250007 .0911800033 .42078000 C $7.63252000 \quad 3.69747000 \quad 33.26748000$ C $8.757890003 .78361000 \quad 32.54318000$ $\begin{array}{llll}\text { C } 8.75789000 & 3.78361000 & 32.54318000 \\ \text { C } 8.82805000 & 3.13096000 & 31.26520000\end{array}$ C 8.867040001 .8075300028 .75019000 C $7.724180001 .73865000 \quad 29.57232000$ C $7.67637000 \quad 2.37700000 \quad 30.80138000$ $\begin{array}{llll}\text { C } 6.50852000 & 2.32385000 & 31.62798000\end{array}$ C $6.49700000 \quad 2.97117000 \quad 32.80898000$

$\begin{array}{lllll}\text { C } 6.49700000 & 2.97117000 & 32.80898000 \\ \text { H } 8.11083717 & 4.99816714 & 29.29095612\end{array}$ H 6.936061745 .6388212831 .35437768 H $5.765278916 .30706637 \quad 33.43260679$ H $5.623901681 .78109008 \quad 31.29803887$ H $12.50089986-0.3813786121 .65975014$ H $14.46107193 \quad 0.87030090 \quad 22.45538377$ $\begin{array}{llll}\text { H } 14.46107193 & 0.87030090 & 22.45538377 \\ \text { C } 12.43874000 & 0.11187000 & 22.63087000\end{array}$ $\begin{array}{llll}\text { C } & 12.43874000 & 0.11187000 & 22.63087000 \\ \text { C } 11.31337000 & 0.02573000 & 23.35517000\end{array}$ C $11.24321000 \quad 0.67838000 \quad 24.63314000$ $\begin{array}{llll}\text { C } 11.20422000 & 2.00180000 & 27.14815000\end{array}$ $\begin{array}{lllll}C & 12.34708000 & 2.07069000 & 26.32603000\end{array}$ C 12.347880002 .0706908026 .32603080 696000 C 13.562730001 .4854900024 .27036000 C $13.57426000 \quad 0.83816000 \quad 23.08937000$ H 14.427880352 .0497078024 .62030153 F 10.665585213 .4401991922 .58118443 H $10.497748413 .76978510 \quad 25.14909107$ $\begin{array}{lllll}H & 13.21409820 & 2.63715476 & 26.67110928\end{array}$ C 9.955430003 .2124900030 .46278000 $\begin{array}{llll}\text { C } 10.01731000 & 2.57103000 & 29.20800000\end{array}$ C $11.14912000 \quad 2.6471900028 .39105000$ H $9.60753492 \quad 4.35220260 \quad 32.91894451$ H $10.82010433 \quad 3.78300197 \quad 30.80626193$ $\begin{array}{llll}H & 12.01511137 \quad 3.21830788 & 28.73095987\end{array}$ H $2.94843673 \quad 6.98313371 \quad 28.64614755$

Figure S16: Atomic positions used for the $2,3-\mathrm{F}_{2} \mathrm{PEN}$ dimers. Coordinates given in $\AA$. 
F $-1.52363403 \quad 3.217200895 .73719366$

F $1.97058157-5.46981652 \quad 2.69767193$

F $3.51278358-3.21677514-2.02457452$

F 0.012181415 .478394921 .02068699

C $2.34092000-4.911950001 .51221000$

C $2.06887800-3.516040001 .35073000$

C $1.42864000-2.74207000 \quad 2.29811000$

H $1.11609357 \quad-3.20086816 \quad 3.23588186$

C $1.20408000-1.376560002 .09505000$

C $0.57752000-0.574950003 .06669000$

H $0.26849757-1.037542734 .00636183$

C $0.34973000 \quad 0.77950000 \quad 2.87333000$

C $-0.263680001 .59493000 \quad 3.84636000$

H -0.569887051 .152873264 .79368518$

C $-0.49090000 \quad 2.94109000 \quad 3.62459000$

C $-1.13748000 \quad 3.795220004 .56435000$

C $-1.36182000 \quad 5.08609000 \quad 4.37653000$

H -1.855531635 .676617135 .14566222$

C $-0.97181000 \quad 5.69974000 \quad 3.12421000$

H $-1.15765542 \quad 6.75333783 \quad 2.93231819$

C $-0.36920000 \quad 4.92301000 \quad 2.20525000$

C $-0.08693000 \quad 3.54368000 \quad 2.37296000$

C $0.54926000 \quad 2.76971000 \quad 1.41726000$

H 0.871846793 .233895320 .48604935

C 0.774530001 .390380001 .60854000

C $1.39980000 \quad 0.59430000 \quad 0.65215000$

H $1.730268631 .05385079-0.28116400$

C $1.61069000-0.76844000 \quad 0.84343000$

C $2.24557000-1.58388000-0.12821000$

H $2.56424926-1.12757303-1.06501879$

C $2.47257000-2.92450000 \quad 0.07831000$

C $3.11555000-3.78693000-0.85174000$

C $3.33094000-5.09715000-0.65977000$

H $3.83185061-5.69076728-1.42034246$

C $2.93571000-5.67486000 \quad 0.58492000$

F $2.25131228 \quad 3.21520154 \quad 5.73468026$

F $5.74106484-5.473990312 .69161839$

F $7.28835036-3.21859614-2.02680944$

F 3.782942245 .474121991 .01471007

C $6.12242000-4.911950001 .51221000$

C $5.85037000-3.516040001 .35073000$

C $5.21014000-2.74207000 \quad 2.29811000$

H $4.88974765 \quad-3.28235436 \quad 3.23209919$

C $4.98558000-1.376560002 .09505000$

C $4.35902000-0.574950003 .06669000$

H $4.04190333-1.039790544 .00195172$

C $4.13123000 \quad 0.77950000 \quad 2.87333000$

C 3.517820001 .594930003 .84636000

H 3.197931111 .148835654 .78700201

C $3.290600002 .94109000 \quad 3.62459000$

C 2.644020003 .795220004 .56435000

C $2.41968000 \quad 5.086090004 .37653000$

H 1.912596235 .673014095 .13905985

C 2.809690005 .699740003 .12421000

H 2.612219616 .750044362 .92754248

C 3.412300004 .923010002 .20525000

C $3.69457000 \quad 3.54368000 \quad 2.37296000$

C $4.33076000 \quad 2.76971000 \quad 1.41726000$

H $4.645339693 .23251327 \quad 0.48224760$

C 4.556030001 .390380001 .60854000

C $5.181300000 .59430000 \quad 0.65215000$

H $5.503695881 .05170091-0.28567173$

C $5.39219000-0.768440000 .84343000$

C $6.02707000-1.58388000-0.12821000$

H $6.33252533-1.13150112-1.07157598$

C $6.25407000-2.92450000 \quad 0.07831000$

C $6.89705000-3.78693000-0.85174000$

C $7.11244000-5.09715000-0.65977000$

H 7.60046265 $-5.69412625-1.42667988$

C $6.71721000-5.67486000 \quad 0.58492000$

H $6.88886164-6.73122960 \quad 0.78292428$

H $3.11876801-6.728136960 .78761139$

Figure S17: Atomic positions used for the $1,4,8,11-\mathrm{F}_{4} \mathrm{PEN}$ dimers. Coordinates given in $\AA$. 


\section{References}

[1] Gabioud, R.; Vogel, P. Synthesis and Diels-Alder Reactivity of 5,6,7,8Tetramethylidene-2-bicyclo[2.2.2] octanol and -octanone. Selective Oxidations of the Corresponding Bis(irontricarbonyl) Complexes. Helv. Chim. Acta 1983, 66, 11341147.

[2] Boger, D. L.; Panek, J. S.; Patel, M. Org. Synth. 1992, 70, 79.

[3] van Stokkum, I. H. M.; Larsen, D. S.; van Grondelle, R. Global and target analysis of time-resolved spectra. BBA-Bioenergetics 2004, 165\%, 82-104.

[4] Snellenburg, J. J.; Laptenok, S.; Seger, R.; Mullen, K. M.; Van Stokkum, I. H. M. Glotaran: A Java-based graphical user interface for the R package TIMP. J. Stat. Softw. 2012, 49, 3.

[5] Hohenberg, P.; Kohn, W. Inhomogeneous Electron Gas. Phys. Rev. 1964, 136, B864B871.

[6] Kohn, W.; Sham, L. J. Self-Consistent Equations Including Exchange and Correlation Effects. Phys. Rev. 1965, 140, A1133-A1138.

[7] Hedin, L. New Method for Calculating the One-Particle Green's Function with Application to the Electron-Gas Problem. Phys. Rev. 1965, 139, A796-A823.

[8] Hybertsen, M. S.; Louie, S. G. Electron Correlation in Semiconductors and Insulators: Band Gaps and Quasiparticle Energies. Phys. Rev. B 1986, 34, 5390.

[9] Hanke, W.; Sham, L. J. Many-Particle Effects in the Optical Spectrum of a Semiconductor. Phys. Rev. B 1980, 21, 4656-4673.

[10] Blum, V.; Gehrke, R.; Hanke, F.; Havu, P.; Havu, V.; Ren, X.; Reuter, K.; Scheffler, M. Ab Initio Molecular Simulations with Numeric Atom-Centered Orbitals. Comput. Phys. Commun 2009, 180, 2175 - 2196.

[11] Havu, V.; Blum, V.; Havu, P.; Scheffler, M. Efficient O(N) Integration for AllElectron Electronic Structure Calculation Using Numeric Basis Functions. J. Comput. Phys. 2009, 228, $8367-8379$.

[12] Perdew, J. P.; Burke, K.; Ernzerhof, M. Generalized Gradient Approximation Made Simple. Phys. Rev. Lett. 1996, 77, 3865-3868. 
[13] Tkatchenko, A.; Scheffler, M. Accurate Molecular Van Der Waals Interactions from Ground-State Electron Density and Free-Atom Reference Data. Phys. Rev. Lett. 2009, 102, 073005.

[14] Hirshfeld, F. L. Bonded-Atom Fragments for Describing Molecular Charge Densities. TCA 1977, 44, 129-138.

[15] Sun, H.; Ryno, S.; Zhong, C.; Ravva, M. K.; Sun, Z.; Körzdörfer, T.; Brédas, J.-L. Ionization Energies, Electron Affinities, and Polarization Energies of Organic Molecular Crystals: Quantitative Estimations from a Polarizable Continuum Model (PCM)Tuned Range-Separated Density Functional Approach. JCTC 2016, 12, 2906-2916.

[16] Marom, N.; Caruso, F.; Ren, X.; Hofmann, O. T.; Körzdörfer, T.; Chelikowsky, J. R.; Rubio, A.; Scheffler, M.; Rinke, P. Benchmark of $G W$ methods for azabenzenes. Phys. Rev. B 2012, 86, 245127.

[17] Atalla, V.; Yoon, M.; Caruso, F.; Rinke, P.; Scheffler, M. Hybrid density functional theory meets quasiparticle calculations: A consistent electronic structure approach. Phys. Rev. B 2013, 88, 165122.

[18] Caruso, F.; Atalla, V.; Ren, X.; Rubio, A.; Scheffler, M.; Rinke, P. First-principles description of charge transfer in donor-acceptor compounds from self-consistent manybody perturbation theory. Phys. Rev. B 2014, 90, 085141.

[19] Bruneval, F.; Rangel, T.; Hamed, S. M.; Shao, M.; Yang, C.; Neaton, J. B. MOLGW 1: Many-Body Perturbation Theory Software for Atoms, Molecules, and Clusters. Comput. Phys. Commun 2016, 208, $149-161$.

[20] Bruneval, F. Ionization Energy of Atoms Obtained from GW Self-Energy or from Random Phase Approximation Total Energies. J. Chem. Phys. 2012, 136, 194107.

[21] Weigend, F.; Köhn, A.; Hättig, C. Efficient Use of the Correlation Consistent Basis Sets in Resolution of the Identity MP2 Calculations. J. Chem. Phys. 2002, 116, $3175-3183$.

[22] Yanai, T.; Tew, D. P.; Handy, N. C. A New Hybrid Exchange-Correlation Functional Using the Coulomb-Attenuating Method (CAM-B3LYP). Chem. Phys. Lett. 2004, $393,51-57$. 
[23] Bruneval, F.; Marques, M. A. L. Benchmarking the Starting Points of the GW Approximation for Molecules. J. Chem. Theory Comput. 2013, 9, 324-329.

[24] Vorwerk, C.; Aurich, B.; Cocchi, C.; Draxl, C. Bethe-Salpeter equation for absorption and scattering spectroscopy: implementation in the exciting code. Electron. Struct. 2019, 1, 037001.

[25] Rangel, T.; Hamed, S. M.; Bruneval, F.; Neaton, J. B. An assessment of low-lying excitation energies and triplet instabilities of organic molecules with an ab initio Bethe-Salpeter equation approach and the Tamm-Dancoff approximation. J. Chem. Phys. 2017, 146, 194108.

[26] Jacquemin, D.; Duchemin, I.; Blondel, A.; Blase, X. Benchmark of Bethe-Salpeter for Triplet Excited-States. J. Chem. Theory Comput. 2017, 13, 767-783.

[27] Peach, M. J. G.; Williamson, M. J.; Tozer, D. J. Influence of Triplet Instabilities in TDDFT. J. Chem. Theory Comput. 2011, 7, 3578-3585, PMID: 26598256.

[28] Sears, J. S.; Koerzdoerfer, T.; Zhang, C.-R.; Brédas, J.-L. Communication: Orbital instabilities and triplet states from time-dependent density functional theory and long-range corrected functionals. JCP 2011, 135, 151103.

[29] Mayer, A. C.; Kazimirov, A.; Malliaras, G. G. Dynamics of Bimodal Growth in Pentacene Thin Films. Phys. Rev. Lett. 2006, 97, 105503.

[30] Schiefer, S.; Huth, M.; Dobrinevski, A.; Nickel, B. Determination of the Crystal Structure of Substrate-Induced Pentacene Polymorphs in Fiber Structured Thin Films. J. Am. Chem. Soc. 2007, 129, 10316-10317.

[31] Campbell, R. B.; Robertson, J. M.; Trotter, J. The crystal structure of hexacene, and a revision of the crystallographic data for tetracene. Acta Cryst. 1962, 15, 289-290.

[32] Geiger, T.; Schundelmeier, S.; Hummel, T.; Ströbele, M.; Leis, W.; Seitz, M.; Zeiser, C.; Moretti, L.; Maiuri, M.; Cerullo, G.; et al., Modulating the Electronic and Solid-State Structure of Organic Semiconductors by Site-Specific Substitution: The Case of Tetrafluoropentacenes. Chem. Eur. J. 2020, 26, 3420-3434.

[33] Siegrist, T.; Kloc, C.; Schön, J. H.; Batlogg, B.; Haddon, R. C.; Berg, S.; Thomas, G. A. Enhanced Physical Properties in a Pentacene Polymorph. Angew. Chem. Int. Ed. 2001, 40, 1732-1736. 
[34] Shen, B.; Geiger, T.; Einholz, R.; Reicherter, F.; Schundelmeier, S.; MaichleMössmer, C.; Speiser, B.; Bettinger, H. F. Bridging the Gap between Pentacene and Perfluoropentacene: Synthesis and Characterization of 2,3,9,10-Tetrafluoropentacene in the Neutral, Cationic, and Dicationic States. J. Org. Chem. 2018, 83, 3149-3158.

[35] Cocchi, C.; Prezzi, D.; Ruini, A.; Caldas, M. J.; Molinari, E. Optical Properties and Charge-Transfer Excitations in Edge-Functionalized All-Graphene Nanojunctions. $J$. Phys. Chem. Lett. 2011, 2, 1315-1319.

[36] Cocchi, C.; Prezzi, D.; Ruini, A.; Caldas, M. J.; Molinari, E. Electronics and optics of graphene nanoflakes: edge functionalization and structural distortions. J. Phys. Chem. C 2012, 116, 17328-17335.

[37] De Corato, M.; Cocchi, C.; Prezzi, D.; Caldas, M. J.; Molinari, E.; Ruini, A. Optical Properties of Bilayer Graphene Nanoflakes. J. Phys. Chem. C 2014, 118, 23219 23225.

[38] Fuchibe, K.; Shigeno, K.; Zhao, N.; Aihara, H.; Akisaka, R.; Morikawa, T.; Fujita, T.; Yamakawa, K.; Shimada, T.; Ichikawa, J. Pinpoint-fluorinated polycyclic aromatic hydrocarbons (F-PAHs): Syntheses of difluorinated subfamily and their properties. J. Fluor. Chem 2017, 203, 173-184.

[39] Hummer, K.; Ambrosch-Draxl, C. Oligoacene exciton binding energies: Their dependence on molecular size. Phys. Rev. B 2005, 71, 081202.

[40] Cudazzo, P.; Gatti, M.; Rubio, A. Excitons in molecular crystals from first-principles many-body perturbation theory: Picene versus pentacene. Phys. Rev. B 2012, 86, 195307.

[41] Berkelbach, T. C.; Hybertsen, M. S.; Reichman, D. R. Microscopic theory of singlet exciton fission. III. Crystalline pentacene. J. Chem. Phys. 2014, 141, 074705.

[42] Hestand, N. J.; Yamagata, H.; Xu, B.; Sun, D.; Zhong, Y.; Harutyunyan, A. R.; Chen, G.; Dai, H.-L.; Rao, Y.; Spano, F. C. Polarized absorption in crystalline pentacene: theory vs experiment. J. Phys. Chem. C 2015, 119, 22137-22147.

[43] Cocchi, C.; Breuer, T.; Witte, G.; Draxl, C. Polarized absorbance and Davydov splitting in bulk and thin-film pentacene polymorphs. Phys. Chem. Chem. Phys. 2018, 20, 29724-29736. 
[44] Valencia, A. M.; Guerrini, M.; Cocchi, C. Ab Initio Modelling of Local Interfaces in Doped Organic Semiconductors. Phys. Chem. Chem. Phys. 2020, 22, 3527-3538.

[45] Kasha, M.; Rawls, H. R.; El-Bayoumi, M. A. The exciton model in molecular spectroscopy. Pure Appl. Chem. 1965, 11, 371-392. 